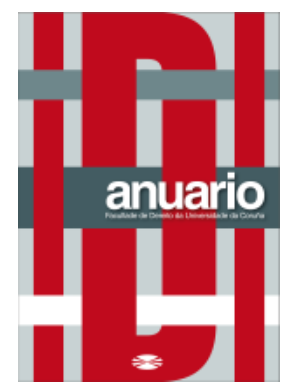

Anuario da Facultade de Dereito da Universidade da Coruña

Vol. 21 (2017), pp. 192-228

ISSNe: 2530-6324 || ISSN: 1138-039X

DOI: https://doi.org/10.17979/afdudc.2017.21.0.3278

\title{
FRACCIONAMIENTO DEL CONTRATO Y DIVISIÓN EN LOTES. POSIBILIDAD DE LIMITAR EL NÚMERO DE LOTES A LOS QUE UN OPERADOR ECONÓMICO PUEDA LICITAR O ADJUDICARSE A CADA LICITADOR
}

\author{
MARÍA DEL CARMEN RODRÍGUEZ MARTÍN-RETORTILLO \\ Profesora interina de Derecho Administrativo \\ Universidade da Coruña
}

\begin{abstract}
Resumo: En este trabajo se efectúa un análisis del tema partiendo de los antecedentes históricos hasta la nueva regulación de la cuarta generación de Directivas comunitarias y el PLCSP. En consonancia con el objetivo de favorecer la concurrencia de las PYME, la Directiva 2014/24/UE dispone que se deberá justificar la no división en lotes. A su vez, no se podrá fraccionar el contrato con la finalidad de disminuir la cuantía del mismo y eludir así los requisitos de publicidad o los relativos al procedimiento de adjudicación que correspondan. Respecto a la limitación en el número de lotes en que los operadores pueden concurrir o la limitación del número de lotes que se puedan adjudicar a un solo licitador, debe hacerse previo el correspondiente estudio que garantice el interés público y la eficiencia de la decisión y las condiciones del mercado, favoreciendo la concurrencia.
\end{abstract}

Palabras clave: fraccionamiento; división; lotes; limitar; objeto.

Abstract: In this paper we analyse the subject starting from its historical background to the new regulation of the fourth generation of Community Directives and the Public Sector Contract Law Project (PLCSP). In accordance with the objective of encouraging the participation of small and medium-size companies (PYME), EU's Directive 2014/24 provides that non-division into lots should be justified. In a similar way, the contract cannot be divided in order to reduce its amount and advertising requirements or those related to the award procedure which apply. As regards the limitation to the number of lots in which operators can attend, or the limitation to the number of lots that can be 
awarded to a single bidder, this must be done prior to the corresponding study that guarantees the public interest, the efficiency of the decision and the market conditions, favoring competition.

Keywords: subdivision; division; lots; to limit; object.

SUMARIO: I. CUESTIONES PREVIAS. II. ANTECEDENTES HISTÓRICOS. III. SU REGULACIÓN EN LAS DIRECTIVAS EUROPEAS Y EN OTROS DOCUMENTOS EUROPEOS DE CONTRATACIÓN, ASÍ COMO EN LA JURISPRUDENCIA DEL TRIBUNAL DE JUSTICIA DE LA UNIÓN EUROPEA. 3.1 Antecedentes. 3.2. Código Europeo de Buenas Prácticas para facilitar el acceso de las PYME a los Contratos Públicos, Comisión de las Comunidades Europeas de 25 de junio de 2008. 3.3. Directiva 2014/23/UE del Parlamento Europeo y del Consejo de 26 de febrero de 2014 relativa a la adjudicación de contratos de concesión. 3.4. Directiva 2014/24/UE del Parlamento Europeo y del Consejo, de 26 de febrero de 2014, sobre contratación pública y por la que se deroga la Directiva 2004/18/CE. 3.5. Directiva 2014/25/UE del Parlamento Europeo y del Consejo de 26 de febrero de 2014 relativa a la contratación por entidades que operan en los sectores del agua, la energía, los transportes y los servicios postales y por la que se deroga la Directiva 2004/17/CE. IV. PROYECTO DE LEY DE CONTRATOS DEL SECTOR PÚBLICO, POR LA QUE SE TRANSPONEN AL ORDENAMIENTO JURÍDICO ESPAÑOL LAS DIRECTIVAS DEL PARLAMENTO EUROPEO Y DEL CONSEJO, 2014/23/UE Y 2014/24/UE, DE 26 DE FEBRERO DE 2014. 4.1. Fraccionamiento y división en lotes. 4.2. Necesidad de justificación de la no división en lotes. 4.3. Motivos válidos para justificar la no división en lotes. 4.4. Limitaciones del número de lotes para los que un mismo candidato o licitador pueda presentar oferta y del número de lotes que pueden adjudicarse a cada licitador. A. Limitación del número de lotes para los que un mismo candidato o licitador pueda presentar oferta. B. Limitación del número de lotes que pueden adjudicarse a cada licitador. Criterios de aplicación. C. Disposiciones comunes. V. OFERTA INTEGRADORA. VI. POSIBILIDAD DE RESERVAR DETERMINADOS LOTES A CENTROS ESPECIALES DE EMPLEO Y EMPRESAS DE INSERCIÓN. VII. CONCLUSIONES. VIII. BIBLIOGRAFÍA.

\section{CUESTIONES PREVIAS}

Desde hace muchos años en numerosos informes del Tribunal de Cuentas y de los Órganos equivalentes de las Comunidades Autónomas se concluye que algunas Administraciones y determinados Entes del Sector público han efectuado una utilización reiterada del fraccionamiento del objeto del contrato, en supuestos en los que no procede, con la finalidad de disminuir la cuantía del mismo y eludir así los requisitos de publicidad ${ }^{1}$ o los relativos al procedimiento de adjudicación. Si bien se puede apreciar que últimamente se ha reducido significativamente esta tendencia, todavía vemos como en algunos casos se presentan dentro de cada anualidad presupuestaria un

\footnotetext{
${ }^{1}$ Vid. MORENO MOLINA, J.A., Los principios generales de la contratación administrativa, Ed. Bomarzo, Albacete, 2006.
} 
encadenamiento de pequeñas facturas que acumuladas también superan los límites del contrato menor, o se divide su objeto en varios contratos para su adjudicación por procedimiento negociado ${ }^{2}$.

Herrera Campa ${ }^{3}$ define el fraccionamiento como "la división artificial en varios expedientes de un gasto que constituye una unidad, realizada por el gestor del mismo y que tiene como consecuencia la elusión de la aplicación de una norma que, en caso de no haberse realizado tal fraccionamiento, le resultaría plenamente aplicable. La posibilidad de tal elusión mediante el fraccionamiento del gasto surge, precisamente, cuando esa misma norma dispone su aplicación en función de la superación o no de determinados umbrales cuantitativos".

Antes de la nueva Directiva 2014/24/UE, el órgano de contratación, una vez acreditada la necesidad de celebrar un contrato, y desde una adecuada planificación, debía valorar previamente a la convocatoria de una licitación si es más ventajoso para el interés público licitar en un único lote o en varios lotes, en este caso justificándolo en el expediente.

Esta valoración entendemos que se efectúa desde una triple perspectiva:

-En primer lugar, determinando si el contrato es susceptible de contratación independiente, mediante su división en lotes, que es lo que la doctrina ha denominado "la unidad operativa o funcional", es decir, si son elementos inseparables para el logro de una misma finalidad o si son imprescindibles para el correcto funcionamiento de aquello que se pretende conseguir mediante la celebración del contrato ${ }^{4}$.

-En segundo lugar, observando las limitaciones por razón del procedimiento de adjudicación a utilizar, pues la división del objeto no puede hacerse para eludir los requisitos exigibles al procedimiento de adjudicación, es decir, si el contrato por razón de la cuantía debe tramitarse por procedimiento abierto o restringido, no puede dividirse el objeto en varios contratos menores o negociados, pues en este caso estaríamos ante un fraude de ley. La jurisprudencia ha declarado en estos casos que es nulo el contrato,

\footnotetext{
${ }^{2}$ El Tribunal de Cuentas en su informe de 13 de enero de 2017 indica que "se han observado supuestos en los que, por las circunstancias concurrentes en los expedientes de contratación, existen indicios de haberse producido un posible fraccionamiento del objeto del contrato, ya que se trata de contratos menores de servicios y de suministro con el mismo objeto, o vinculados entre sí por una misma finalidad adjudicados en la mayor parte de los casos a la misma empresa-, y cuyo importe conjunto supera el límite máximo cuantitativo previsto en el TRLCSP. En estos supuestos, a la vista del carácter reiterado y previsible de los servicios, de la similitud de las prestaciones, así como del fin único de las diversas contrataciones, habría sido precisa la realización de una planificación más racional de las necesidades y de las actuaciones para cubrirlas; de modo que, en lugar de proceder a la celebración de distintos contratos menores, se hubiera efectuado una contratación única por el importe conjunto de las prestaciones, a través del procedimiento establecido para cada caso, lo que, además, hubiera contribuido a dotar de una mayor publicidad y concurrencia a la contratación".

${ }^{3}$ HERRERA CAMPA, J.J., "Análisis normativo del fraccionamiento del gasto", Revista Cuenta con IGAE, Edición y Distribución: Subdirección General de Información, Documentación y Publicaciones, $\mathrm{n}^{\circ} 13$, Noviembre 2005, pág. 25.

${ }^{4}$ Vid. Informe de la Junta Consultiva de Contratación Administrativa 31/12, de 7 de mayo de 2013: Es decir, el primer requisito que debe cumplirse para que pueda hablarse de fraccionamiento del contrato es que exista una unidad operativa o sustancial entre las diferentes prestaciones (o partes de prestaciones). Así se desprende sin lugar a dudas de la propia Ley de Contratos del Sector Público, que en su apartado 3 se refiere a que "cuando el objeto del contrato admita fraccionamiento y así se justifique debidamente en el expediente, podrá preverse la realización independiente de cada una de sus partes mediante su división en lotes, siempre que éstos sean susceptibles de utilización o aprovechamiento separado y constituyan una unidad funcional, o así lo exija la naturaleza del objeto".
} 
dado este fraccionamiento fraudulento y no justificado del contrato para eludir la aplicación de estos principios y requisitos. Circunstancia muy grave y que infringe los principios de la contratación pública, y que puede conllevar consecuencias de tipo penal, si se dan determinadas circunstancias ${ }^{5}$.

En este sentido Francisco de Paula Aguilera González y José Manuel Modelo Baeza ${ }^{6}$ consideran, al analizar las consecuencias jurídicas del fraccionamiento fraudulento del contrato, que nos encontramos ante un supuesto de nulidad de pleno derecho. De igual modo, José Luis Villar Ezcurra y Jaime Marfá Badaroux ${ }^{7}$ señalan que "es significativa al respecto la sentencia del TSJ País Vasco de 17 de junio de 1999 en la que se decide la nulidad de un contrato administrativo de prestación de servicios, por un lado, por ausencia de expediente de contratación, y por otro, por considerar que se ha fraccionado indebidamente el objeto del contrato para evitar cumplir con los requisitos que imponen los principios de publicidad y concurrencia."

Tampoco es posible fraccionarlo igualmente para eludir los requisitos de aplicación de la normativa y la publicidad comunitaria, tal y como establecían la derogada Directiva 2004/18 en su artículo $9.3^{8}$ y anteriormente los artículos 17.2 de la Directiva 2004/17 ${ }^{9}$, 6.4 de la Directiva $93 / 37^{10}, 5.6$ de la Directiva $93 / 36^{11}$, artículo 7.3 de la Directiva $92 / 50^{12}$, artículo 14.13 de la Directiva $93 / 38^{13}$, artículo 7.2 de la Directiva $71 / 305$ de 26 de julio de 1971, ${ }^{14}$ y ahora establece la Directiva 2014/24 .

-En tercer lugar, desde una racionalidad en la especialidad de las ofertas en el mercado y para favorecer la concurrencia de las PYMES, pues por ejemplo no tiene sentido adquirir en un único lote para un hospital productos que no tienen nada que ver entre sí,

\footnotetext{
${ }^{5}$ Vid. Sentencia del Tribunal Superior de Justicia de Asturias, $n^{\circ} 2 / 2014$, de 6 de mayo.

${ }^{6}$ DE PAUlA AGUILERA GONZÁLEZ, F., y MODELO BAEZA, J.M., "El fraccionamiento en la contratación administrativa local”, El Consultor, n¹7, quincena 15-29 septiembre 2007, pág. 2768.

${ }^{7}$ VILLAR EZCURRA, J.L., y MARFÁ BADAROUX, J., “Artículo 68. Fraccionamiento del objeto del contrato", en AA.VV., Comentarios a la Ley de contratos de las Administraciones Públicas, Tomo II, Ariño y Asociados, Granada, 2003, pág.1131.

${ }^{8}$ Artículo 9.3:

"No podrá fraccionarse ningún proyecto de obra ni ningún proyecto de compra tendente a obtener una determinada cantidad de suministros y/o de servicios con vistas a sustraerlo a la aplicación de la presente Directiva".

9 Artículo 17.2:

"Las entidades adjudicadoras no podrán substraerse a la aplicación de la presente Directiva dividiendo los proyectos de obras o los proyectos de adquisición de productos o de prestación de servicios destinados a obtener una determinada cantidad de suministros o de servicios ni empleando modalidades particulares de cálculo del valor de los contratos".

${ }^{10}$ Artículo 6.4:

"No se podrá fraccionar ninguna obra ni contrato con objeto de sustraerse a la aplicación de la presente Directiva".

${ }^{11}$ Artículo 5.6:

"No podrá fraccionarse ningún proyecto de compra de una cantidad determinada de suministros con el fin de sustraerse a la aplicación de la presente Directiva".

${ }^{12}$ Artículo 7.3:

"La elección del método de valoración de un contrato no podrá utilizarse para sustraer dicho contrato a la aplicación de la presente Directiva, como tampoco podrá fraccionarse ningún proyecto de contratación de un determinado número de servicios con el propósito de sustraerlo a la aplicación del presente artículo".

${ }^{13}$ Artículo 14.13:

"Las entidades contratantes no podrán substraerse a la aplicación de la presente Directiva dividiendo los contratos o empleando modalidades particulares de cálculo del valor de los contratos."

${ }^{14}$ Artículo 7.2:

"Ningún contrato podrá ser fraccionado con el objeto de sustraerlo a la aplicación del presente artículo".
} 
como material quirúrgico, medicamentos y productos farmacéuticos, camas, ordenadores, fotocopiadoras, impresoras, mobiliario, etc... cuando la división en varios lotes, con arreglo a un procedimiento abierto, permite la presentación de los proveedores especializados en cada producto o bien que se incremente la concurrencia, consiguiendo mejores precios.

La racionalidad y especialidad de distribución en lotes abarca también la de los bienes o productos que componen dicho lote, o sublotes, pues en ocasiones se adquieren artículos o productos funcionalmente independientes, pero que tienen cierta vinculación unos con otros, por ejemplo material de oficina, y se agrupan en un mismo lote.

A partir de la entrada en vigor y transcurrido el plazo de transposición de la Directiva 2014/24/UE el órgano de contratación veremos que debe propiciar la división en lotes, facilitando la participación de las pequeñas y medianas empresas, sin que ello suponga el fraccionamiento del contrato, pues en todo caso se deben observar los procedimientos de adjudicación y la normativa y publicidad comunitaria.

Frente a estos posicionamientos se ha defendido que la división en lotes en algún caso afecta a las economías de escala que podía obtener la Administración no dividiendo en lotes.

\section{ANTECEDENTES HISTÓRICOS}

La posibilidad de división del contrato en lotes tiene antecedentes en los pliegos ${ }^{15}$ y normativa contractual española de los siglos $\mathrm{XIX}^{16} \mathrm{y} \mathrm{XX}$. De igual modo, se han establecido restricciones para el fraccionamiento del contrato.

\footnotetext{
${ }^{15}$ Vid. Pliego de condiciones para el suministro de las casas de corrección de mujeres, de 13 marzo 1852: Artículo 16: "Podrán hacerse proposiciones bien para el suministro de una casa de corrección determinada, o bien para todas ellas, pero han de presentarse con distinción las parciales de la general." (Gaceta de Madrid núm. 6476, de 16/03/1852).

Vid. Junta consultiva de la Armada.- Se saca a pública licitación el suministro de lonas y tejidos de fabricación española que se necesitan en los departamentos de Cádiz, Ferrol y Cartagena durante el corriente año y el próximo de 1864. Pliego de condiciones, "Artículo 3. Las proposiciones podrán hacerse bien para desempeñar el suministro en los tres departamentos, en dos o en uno solamente" (Gaceta de Madrid núm. 205, de 24/07/1863).

Vid. Junta Consultiva de la Armada.- Subasta del suministro de jarcias de fabricación española que se necesiten en los departamentos de Cádiz y Ferrol, durante del corriente año y el próximo de 1856. Pliego de condiciones (Gaceta de Madrid núm. 143, de 23/05/1863).

Vid. Dirección general de Beneficencia y Sanidad.- Pliego de condiciones bajo las cuales se saca a pública subasta el suministro de aceite, garbanzos, arroz y judías secas al Hospital del Rey, en Toledo.

Artículo 11: "Se admitirán proposiciones para cada uno de los artículos que se subastan, pero será preferida la que los comprenda a todos, siempre que los precios propuestos no excedan de los fijados en el pliego cerrado". (Gaceta de Madrid núm. 308, de 04/11/1875).

Vid. Pliego de condiciones facultativas bajo las cuales se saca a publica licitación la adquisición de los materiales de hierro que se necesitan en los arsenales de Ferrol y Cartagena para la construcción de cruceros. 14 febrero 1882. Ministerio de Marina.- cláusula 12: "Para facilitar la licitación se divide el suministro en dos lotes, de los cuales el primero comprende el de los materiales que deben entregarse en el arsenal de Ferrol y el segundo el de los que corresponden a Cartagena." (Gaceta de Madrid núm. 49, de 18/02/1882).

Vid. Dirección general de Rentas Estancadas.- Pliego de condiciones bajo las cuales la Hacienda pública contrata la adquisición de 2.500.000 kilogramos de tabaco hoja de las Islas Filipinas, en cinco lotes, de 500.000 kilogramos cada uno, para el suministro de las Fábricas de la Península.
} 
A continuación vamos a referirnos brevemente a su evolución en la normativa, y en especial hasta llegar a la Directiva 2014/24/UE, que establece una nueva regulación de la materia, y a la normativa española de adaptación a la misma, con un proyecto de Ley de Contratos del Sector Público en fase de debate en las Cortes Generales:

1) Real decreto aprobatorio de la instrucción para la contratación de los servicios provinciales y municipales e instrucción a que se refiere dicho Real decreto (Gaceta de Madrid núm. 119, de 29/04/1900).

Es muy importante en cuanto precedente de la prohibición de fraccionamiento, pues esta Instrucción dispone lo siguiente en su artículo 2, último párrafo:

"Por ningún concepto las Corporaciones podrán dividir la materia de contratación en partes o grupos, con el fin de que la cuantía no llegue a la precisa para la celebración de subasta ó concurso, cuando se trate de objetos de una misma clase y de obras para un mismo servicio".

2) Real Decreto e Instrucción de 24 de enero de 1905 para la contratación de servicios provinciales y municipales (Gaceta de Madrid núm. 26, de 26/01/1905).

Sigue la línea de la Instrucción de 1900, al disponer en su artículo 2, último párrafo que: "Por ningún concepto las Corporaciones podrán dividir la materia de contratación en partes o grupos, con el fin de que la cuantía no llegue a la precisa para la celebración de subasta o concurso, cuando se trate de objetos de una misma clase o de obras para un mismo servicio"

3) Real decreto de 22 de mayo de 1923 aprobando la instrucción reformada sobre contratación de los servicios provinciales y municipales y de los correspondientes a los Cabildos insulares de la provincia de Canarias, artículo 2.

4) El Reglamento de 2 de julio de 1924 para la contratación de las obras y servicios a cargo de las entidades Municipales (Gaceta de Madrid de 4/07/1924), que en su artículo $3^{\circ}$, último párrafo, indica que:

"Por ningún concepto podrán las Entidades municipales dividir la materia de contratación en partes o grupos, con el fin de que la cuantía no llegue a la precisa para la celebración de subasta o concurso, cuando se trate de objetos de una misma clase o de obras para un mismo servicio".

En relación con esta cuestión Fernando $\mathrm{Albi}^{17}$ se pregunta "pero ¿que se entenderá por objetos de una misma clase?; ¿en los suministros de material de escritorio deberán englobarse en una misma contrata los utensilios mecánicos para máquinas de escribir y el papel que esta ha de utilizar?; ¿deberán considerarse como medios de un mismo servicio las escobas para la limpieza a mano de la vía pública y las piezas de recambio

Gaceta de Madrid núm. 45, de 14/02/1884, págs. 434 a 435. Departamento: Ministerio de Hacienda.

Vid. Subsecretaría.- Se venden en pública subasta varias puertas, ventanas, vidrieras, hierro viejo, chimeneas, muebles y otros efectos inútiles, comprendidos en tres lotes, con sujeción a las tasaciones verificadas por el Arquitecto de Hacienda y al pliego de condiciones expuesto al público en los patios de este Ministerio. (Gaceta de Madrid núm. 33, de 02/02/1884, pág. 329).

${ }^{16}$ Bases para la redacción del Reglamento de obras y servicios del Cuerpo de Ingenieros del Ejército. De 1892 (Gaceta de Madrid núm. 345, de 10/12/1892) base 33. "Los contratos para las construcciones militares podrán efectuarse de las cinco maneras que a continuación se expresan: (...) $4^{\text {a }}$ Contratando los materiales en diversos lotes, con separación por clases y aparte la mano de obra en destajos con los operarios prácticos e inteligentes para diversas especies de trabajos".

${ }^{17}$ ALBI, F., Los Contratos municipales, Editorial Horizontes, Valencia, 1944, pág. 124. 
de los elementos mecánicos del propio servicio?; Ha de existir en ello, indudablemente un amplio margen de discrecionalidad para cuya aplicación habrá que atender a las circunstancias del caso".

5) El Reglamento de obras, servicios y bienes municipales de 14 de julio de 1924 , (Gaceta de Madrid de 16/07/1914) en su artículo 8, párrafo último, hace una alusión indirecta a la posibilidad de ejecución separada, pero no desarrolla la materia:

"No será obligatoria la división en zonas parciales de la zona general del ensanche, a los efectos administrativos, pudiendo, no obstante, ordenarse los servicios en diferentes secciones o sectores a fin de que las obras que el plan de ensanche abarque puedan ejecutarse escalonada, y separadamente, si así conviniera al Ayuntamiento".

A continuación hay 5 normas que tienen una regulación similar, y que si bien prohíben el fraccionamiento lo circunscriben a cuando el periodo de ejecución corresponda a un mismo presupuesto:

6) Ley de bases de Régimen Local de $1935^{18}$, Base XVIII:

"Con el fin de evitar que los presupuestos parciales, no rebasen las cifras fijadas en los párrafos anteriores, cómo simulación que sustraiga a la obligación de someterse a la subasta o concurso, no podrán fraccionarse los contratos de obras o suministros de la misma índole y finalidad cuando el período de su ejecución sea el que corresponde al mismo presupuesto ordinario".

7) Ley municipal de 31 octubre de $1935^{19}$, artículo 127 :

"No podrá fraccionarse la materia de los contratos municipales en partes o grupos, con el fin de que su cuantía no llegue a la precisa para la celebración de subasta o concurso cuando el período de ejecución corresponda a un solo Presupuesto ordinario".

En el Diccionario de la Administración Española ${ }^{20}$ se señala al respecto lo siguiente:

"luego, a la inversa, si la ejecución corresponde a varios ejercicios, podrá fraccionarse la obra. Si es así, el artículo consigue todo lo contrario de lo que se propone, pues las obras más importantes se pueden sustraer a la subasta o concurso."

8) Ley de 17 de julio de 1945 de bases de Régimen Local ${ }^{21}$, que en la Base 54 dispone que:

"No podrá fraccionarse en partes o grupos la materia de los contrates de obras o servicios, si el período de ejecución corresponde a un solo presupuesto ordinario".

9) Ley de Régimen Local, Decreto de 16 de diciembre de 1950 por el que se aprueba el texto articulado de la Ley de Régimen local de 17 de julio de $1945^{22}$, cuyo artículo 317 estipula que:

"La materia de los contratos de obras y servicios no podrá fraccionarse en partes o grupos, si el periodo de ejecución correspondiere al de un solo Presupuesto ordinario".

\footnotetext{
${ }^{18}$ Gaceta de Madrid núm. 193, de 12/07/1935.

${ }^{19}$ Gaceta de Madrid. núm. 307, de 3/11/1935.

${ }^{20}$ Diccionario de la Administración, Alcubilla, apéndice de 1935.

${ }^{21}$ BOE núm. 199, de 18/07/1945.

22 BOE núm. 363, de 29/12/1950.
} 
10) Reglamento de Contratación de las Corporaciones Locales de 1953, que en su artículo 9 indica lo siguiente:

"1. La materia de los contratos de obras y servicios no podrá fraccionarse en partes o grupos, si el periodo de ejecución correspondiere al de un solo Presupuesto ordinario.

2. El Secretario y el Interventor cuidarán especialmente, bajo su responsabilidad, de que no se infrinja dicha prohibición, y al efecto formularán cuando proceda, dentro de su respectiva competencia, la advertencia de manifiesta ilegalidad en la forma que determina el artículo 232 del Reglamento de Organización, funcionamiento y régimen jurídico de las Corporaciones Locales".

Señala Barros Martínez ${ }^{23}$ que si la ejecución corresponde a varios presupuestos la Corporación podría invertir directamente la consignación de cada uno si no rebasa los límites del artículo 311, apartado f.

11) Decreto de 12 de diciembre de 1958 por el que se aprueba el Reglamento de Contratación de Obras y Servicios de la Marina (BOE núm. 313, de 31/12/1958), que prevé la contratación por lotes en los siguientes preceptos:

- Artículo 30: "En un mismo pliego de condiciones pueden incluirse materiales y efectos que pertenezcan a distintos ramos de la industria o el comercio, pero los jefes facultativos procurarán agruparlos en tantos lotes cuantos sean necesarios para facilitar la contratación de que se trate".

- Artículo 31: “1. En cada lote se comprenderán aquellos materiales o efectos que por su importancia puedan constituir una especialidad en su producción, fabricación o comercio.2. En estos casos las condiciones facultativas y económico-facultativas se fijarán en pliegos independientes, para que puedan ser unidos a cada lote y escriturados separadamente a fin de evitar mayores gastos a los adjudicatarios".

- Artículo 131.2: "En los contratos que estén divididos en lotes, con fianzas independientes, la rescisión solo alcanzará al lote o lotes que la hubieren motivado".

12) Ley 198/1963 de 28 de diciembre de Bases de Contratos del Estado.

Alude a la necesidad de que el proyecto se refiera a una obra completa ${ }^{24}$, como aquellas que son susceptibles de ser entregadas al uso general o al servicio. De igual modo señala que cuando una obra admita fraccionamiento podrán redactarse proyectos independientes siempre que se den cualquiera de estas circunstancias:

a) siempre que estas sean susceptibles de utilización independiente en el sentido del uso general o del servicio,

b) o puedan ser sustancialmente definidas y preceda autorización administrativa que funde la conveniencia del referido fraccionamiento.

13) El Decreto 923/1965 por el que se aprueba el texto articulado de la Ley de Contratos del Estado, desarrolla el concepto de obra completa ${ }^{25}$.

\footnotetext{
${ }^{23}$ BARROS MARTíNEZ, E., Derecho Local de España, Instituto Editorial Reus, Madrid, 1951, pág. 287.

${ }^{24}$ Base III:

" $1.1^{\circ}$. Los proyectos deberán referirse a obras completas, sin perjuicio de que se hagan las oportunas salvedades cuando aquellas sean susceptibles de descomponerse en partes sustancialmente definidas".

${ }^{25}$ Artículo 21:
} 
La STS 15 de febrero de 1984 alude al principio de unidad de obra para evitar estériles proyectos parciales que pudieran quedar inconclusos.

14) Decreto 3354/1967, de 28 de diciembre, por el que se aprueba el Reglamento General de Contratación para la aplicación de la Ley de Contratos del Estado, texto articulado aprobado por Decreto 923/1965 de 8 de abril.

Reproduce en sus artículos 58 y 59, el artículo 21 del Texto articulado de la ley, relativos a la obra completa $^{26}$ y obra que admite fraccionamiento, añadiendo en el artículo 59 cúal es el órgano competente para su autorización. ${ }^{27}$. Por su parte en el artículo 64, apartado segundo, señala que en la memoria se figurará la manifestación expresa y justificada de que el proyecto comprende una obra completa o fraccionada ${ }^{28}$.

15) Decreto 3410/1975, de 25 de noviembre, por el que se aprueba el Reglamento general de Contratación del Estado.

El artículo 59 de esta norma es idéntico al 59 del Reglamento anterior ${ }^{29}$. El artículo 64 relativo al contenido de la Memoria del proyecto, último párrafo, es similar al 64 del anterior Reglamento. ${ }^{30}$

"Los proyectos deberán referirse necesariamente a obras completas, entendiéndose por tales las susceptibles de ser entregadas al uso general o al servicio correspondiente, sin perjuicio de las ulteriores ampliaciones de que posteriormente puedan ser objeto, y comprenderán todos y cada uno de los elementos que sean precisos para la utilización de la obra.

Cuando una obra admita fraccionamiento podrán redactarse proyectos independientes relativos a cada una de sus partes, siempre que estas sean susceptibles de utilización independiente en el sentido del uso general o del servicio, o puedan ser sustancialmente definidas y preceda autorización administrativa que funde la conveniencia del referido fraccionamiento".

${ }^{26}$ La STS de 15 de febrero de 1984 acogió dicho criterio al entender consagrado "el principio de unidad de obra para evitar estériles proyectos parciales que pudieran quedar inconclusos con el devenir del tiempo, y para impedir posibles fraccionamientos de la obra conducentes a alterar el régimen de contratación que corresponda" lo que implicaba, según la sentencia mencionada, que por obra completa ha de entenderse las susceptibles de ser entregadas al uso general o al servicio correspondiente, sin perjuicio de las ulteriores ampliaciones de que posteriormente puedan ser objeto (Resolución del TACRC 571/20169).

${ }^{27}$ Artículo 58:

"Los proyectos deberán referirse necesariamente a obras completas. entendiéndose por tales las susceptibles de ser entregadas al uso general o al servicio correspondiente, sin perjuicio de las ulteriores ampliaciones de que posteriormente puedan ser objeto y comprenderán todos y cada uno de los elementos que sean precisos para la utilización de la obra. (artículo 21 L. C. E.) Los proyectos relativos a obras de reforma, reparación o conservación deberán comprender todas las necesarias para lograr el fin propuesto. Sin estos requisitos no podrán ser aprobados los proyectos ni el gasto que represente la ejecución de las obras que comprendan".

Artículo 59:

"Cuando una obra admita fraccionamiento podrán redactarse proyectos independientes relativos a cada una de sus partes, siempre que éstas sean susceptibles de utilización independiente, en el sentido del uso general o del servicio, o puedan ser sustancialmente definidas y preceda autorización administrativa que funde la conveniencia del referido fraccionamiento. (artículo 21 L. C. E.).

La autorización exigida será competencia del Jefe del Departamento o autoridad en quien haya expresamente delegado esta facultad".

${ }^{28}$ Artículo 64:

“(...) Igualmente, en dicha Memoria figurará la manifestación expresa y justificada de que el proyecto comprende una obra completa o fraccionada, según el caso, en el sentido exigido por el artículo 56 o en el permitido por el 59, respectivamente. De estar comprendido en un anteproyecto aprobado, se hará constar esta circunstancia”.

${ }^{29}$ Artículo 59:

"Cuando una obra admita fraccionamiento podrán redactarse proyectos independientes relativos a cada una de sus partes, siempre que éstas sean susceptibles de utilización independiente, en el sentido del uso 
16) Real Decreto 2528/1986, de 28 de noviembre, por el que se modifica el Reglamento General de Contratación del Estado para adaptarlo al Real Decreto Legislativo 931/1986, de 2 de mayo, y a las Directivas de la Comunidad Económica Europea.

Los dos primeros apartados son similares a la redacción anterior, no obstante, añade en su apartado 3, articulo $59^{31}$ que "sin perjuicio de lo establecido en los párrafos anteriores, no podrá fraccionarse una obra con objeto de disminuir la cuantía del contrato a efectos de soslayar los requisitos de concurrencia."

A su vez, en el artículo 238.3, en relación con el contrato de suministro, se indica igualmente que "no podrá fraccionarse la contratación de suministros con el fin de eludir los requisitos de concurrencia". Alude asimismo a los lotes en los artículos $238.2^{32}$ y $244.8^{33}$.

La Junta Consultiva, en Informe 14/92, de 17 de junio de 1992, señaló que:

"En los casos de licitación por lotes la garantía provisional debe fijarse separadamente para cada lote".

17) La Ley 13/1995, de Contratos de las Administraciones Públicas regula en diversos preceptos el fraccionamiento de los contratos y la división en lotes ${ }^{34}$.

El Consejo de Estado en su Dictamen de 21 de mayo de 1992, al anteproyecto ${ }^{35}$, señala que éste "consagra, con carácter general, la prohibición de fraccionamiento con objeto

general del servicio o puedan ser sustancialmente definidas y preceda autorización administrativa que funde la conveniencia del referido fraccionamiento (artículo 21 L C. E) La autorización exigida en este último caso será. competencia del Jefe del Departamento o autoridad en quien haya expresamente delegado esta facultad, y habrá de ser debidamente motivada".

${ }^{30}$ Artículo 64:

"Igualmente, en dicha Memoria figurará la manifestación expresa y justificada de que el proyecto comprende una obra completa o fraccionada, según el caso, en el sentido exigido por el artículo 58 o en el permitido por el 59, respectivamente. De estar comprendido en un anteproyecto aprobado, se hará constar esta circunstancia".

${ }^{31}$ Artículo 59:

"Cuando una obra admita fraccionamiento podrán redactarse proyectos independientes relativos a cada una de sus partes, siempre que éstas sean susceptibles de utilización independiente, en el sentido del uso general o del servicio, o puedan ser sustancialmente definidas y preceda autorización administrativa que funde la conveniencia del referido fraccionamiento (artículo 21 LCE).

La autorización exigida en este último caso será competencia del órgano de contratación y habrá de ser debidamente motivada.

Sin perjuicio de lo establecido en los párrafos anteriores, no podrá fraccionarse una obra con objeto de disminuir la cuantía del contrato a efectos de soslayar los requisitos de concurrencia".

${ }^{32}$ Artículo 238.2:

"En el caso de suministros homogéneos que pudieran dar lugar a la celebración simultánea de contratos por lotes separados, se tomará como base de la licitación el valor estimado de la totalidad de dichos lotes.

Sin perjuicio de lo dispuesto en el artículo anterior, el pliego de bases para los contratos de suministro deberá contener, atendiendo a su naturaleza, los siguientes conceptos: (...) 8. Posibilidad de licitar por la totalidad del suministro, por partidas independientes o por los lotes que se establezcan dentro de cada partida".

${ }^{33}$ Artículo 244.8:

"Posibilidad de licitar por la totalidad del suministro, por partidas independientes o por los lotes que se establezcan dentro de cada partida".

${ }^{34}$ Artículos 69, 136 y 205.

35 "La prohibición de fraccionamiento de los contratos, a efectos de eludir normas imperativas por razón de la cuantía, es uno de los principios básicos de la legislación de contratos del Estado, que también proclaman las Directivas comunitarias, con la finalidad concreta de evitar que mediante el 
de disminuir la cuantía del mismo y eludir así los requisitos de publicidad, el procedimiento o la forma de adjudicación que corresponda".

Así, en su artículo $69^{36}$, apartado $2^{\circ}$, establece dos supuestos en que no es posible el fraccionamiento de los contratos:

No podrá fraccionarse un contrato con objeto de disminuir la cuantía del mismo, y eludir así los requisitos:

a) de publicidad,

b) el procedimiento o la forma de adjudicación que corresponda.

Señalaba a continuación que:

"No obstante, cuando el objeto admita fraccionamiento ${ }^{37}$, justificándolo debidamente en el expediente, podrá preverse en el mismo la realización independiente de cada una de sus partes, mediante su división en lotes, siempre que:

a) estas sean susceptibles de utilización o aprovechamiento separado

b) o así lo exija la naturaleza del objeto".

Sin embargo, este apartado fue modificado por la Ley 53/1999, por la que se modifica la Ley $13 / 1995^{38}$, suprimiendo el párrafo último del artículo 69.3: "Si el contenido de las

fraccionamiento se puedan eludir las normas de publicidad en el Diario Oficial de las Comunidades Europeas.

El artículo 64 del Anteproyecto, en su último párrafo, consagra, con carácter general, la prohibición de fraccionamiento con objeto de disminuir la cuantía del mismo y eludir así los requisitos de publicidad, el procedimiento o la forma de adjudicación que corresponda, generalizando lo que para el contrato de obras se dispone en el último párrafo del artículo 59 del Reglamento General de Contratación del Estado y para el contrato de suministros en el artículo 238, párrafo noveno 3, -según la redacción dada a los mismos por el Real Decreto 2528/1986, de 25 de noviembre- y que, únicamente con carácter supletorio, se aplicaban al resto de contratos administrativos.

En definitiva, el Anteproyecto eleva a rango legal la prohibición, la generaliza a todos los contratos y especifica los efectos que tratan de impedirse con la prohibición. El Consejo, apreciando favorablemente la redacción del artículo 64, estima, no obstante, que debiera considerarse la conveniencia de completar la prohibición que establece concretando, en los términos que se estimaran procedentes, los efectos de su inobservancia".

${ }^{36}$ Artículo 69:

"1. EI expediente deberá abarcar la totalidad del objeto del contrato y comprenderá todos y cada uno de los elementos que sean precisos para ello.

2. No podrá fraccionarse un contrato con objeto de disminuir la cuantía del mismo y eludir así los requisitos de publicidad, el procedimiento o la forma de adjudicación que corresponda.

3. No obstante, cuando el objeto admita fraccionamiento, justificándolo debidamente en el expediente, podrá preverse en el mismo la realización independiente de cada una de sus partes, mediante su división en lotes, siempre que estas sean susceptibles de utilización o aprovechamiento separado o así lo exija la naturaleza del objeto.

Si el contenido de las diferentes partes fuera sustancialmente idéntico, podrá celebrarse un solo contrato para la adjudicación de las mismas".

${ }^{37}$ La sentencia del TSJ de Baleares de 30 noviembre de 1999 admite la división en lotes si se encuentra justificada.

${ }^{38}$ Ley 53/1999, por la que se modifica la Ley 13/1995.

Artículo 69. Se modifica el título del artículo y se da nueva redacción al apartado 3:

“3. Cuando el objeto admita fraccionamiento, justificándolo debidamente en el expediente, podrá preverse en el mismo la realización independiente de cada una de sus partes, mediante su división en lotes, siempre que éstas sean susceptibles de utilización o aprovechamiento separado o así lo exija la naturaleza del objeto". 
diferentes partes fuera sustancialmente idéntico, podrá celebrarse un solo contrato para la adjudicación de las mismas".

Los Artículos 136 y el $205^{39}$ regulan el cálculo del valor estimado.

Cuando la obra está dividida en varios lotes y cada lote constituya un contrato, el importe de cada uno se tendrá en cuenta para la determinación de la cuantía a efectos del artículo 135. No obstante, cuando el importe acumulado de los lotes sea igual o superior a la cifra indicada en el artículo anterior se aplicarán a todos los lotes, a los efectos de publicidad, las disposiciones del mismo.

En relación con los suministros se remite a dicho artículo sustituyendo el importe.

18) Ley 48/1998 sobre procedimientos de contratación en los sectores del agua, la energía, los transportes y las telecomunicaciones, por la que se incorporan al ordenamiento jurídico español las Directivas 93/38/CEE y 92/13/CEE (BOE de 31/12/1998), que indica lo siguiente en su artículo 9.13:

"Las entidades contratantes no podrán sustraerse a la aplicación de la presente Ley fraccionando los contratos o empleando modalidades particulares de cálculo del importe de los contratos".

19) Real Decreto 725/1989, sobre anticipos de caja fija artículo 2, último párrafo.

A efectos de aplicación de estos límites, no podrán acumularse en un solo justificante pagos que se deriven de diversos gastos, ni fraccionarse un único gasto en varios pagos.

20) Ley 53/1999 por la que se modifica la Ley 13/1995, que como hemos expuesto modificó la redacción del artículo 68 de la Ley 13/1995.

21) R. Decreto legislativo $2 / 2000$, por el que se aprueba el texto refundido de la Ley de Contratos de las Administraciones Públicas, que regula en el artículo 68 el fraccionamiento del objeto del contrato $^{40}$ de forma idéntica a la ley 13/95, en su redacción dada por la Ley 53/1999.

\footnotetext{
${ }^{39}$ Artículo 136. División por lotes:

"1. Cuando la obra esté dividida en varios lotes y cada lote constituya un contrato, el importe de cada uno se tendrá en cuenta para la determinación de la cuantía a efectos del artículo anterior. No obstante, cuando el importe acumulado de los lotes sea igual o superior a la cifra indicada en el artículo anterior se aplicarán a todos los lotes, a los efectos de publicidad, las disposiciones del mismo.

2. Sin embargo, el órgano de contratación podrá considerar solamente el importe individualizado de cada lote cuando sea inferior a 136.331 .441 pesetas, con exclusión del Impuesto sobre el Valor Añadido, siempre que el importe acumulado de dichos lotes no sea superior al 20 por 100 del importe acumulado de todos los lotes en los que está dividida la obra".

Artículo 205. División por lotes:

"Cuando exista división en varios lotes, a efectos de la determinación de la cuantía a que se refiere el artículo anterior. se aplicarán las reglas establecidas en el artículo 136, sustituyendo la cifra de 136.331.441 pesetas que figura en su apartado 2 por la de 10.906 .483 pesetas".

${ }^{40}$ Artículo 68:

"1. El expediente deberá abarcar la totalidad del objeto del contrato y comprenderá todos y cada uno de los elementos que sean precisos para ello.

2. No podrá fraccionarse un contrato con objeto de disminuir la cuantía del mismo y eludir así los requisitos de publicidad, el procedimiento o la forma de adjudicación que corresponda.

3. Cuando el objeto admita fraccionamiento, justificándolo debidamente en el expediente, podrá preverse en el mismo la realización independiente de cada una de sus partes, mediante su división en lotes, siempre que éstas sean susceptibles de utilización o aprovechamiento separado o así lo exija la naturaleza del objeto".
} 
En relación con la justificación del fraccionamiento, la Resolución de 22 de abril de 2005 del Tribunal de Cuentas, por la que se aprueba la Instrucción general relativa a la remisión al citado órgano de los extractos de los expedientes de contratación, incluye en su anexo II, la necesidad de incluir dicha justificación ${ }^{41}$.

Los artículos $136^{42}$ y 204 regulan el cálculo del valor estimado:

"Cuando la obra está dividida en varios lotes y cada lote constituya un contrato, el importe de cada uno se tendrá en cuenta para la determinación de la cuantía a efectos del artículo 135. No obstante, cuando el importe acumulado de los lotes sea igual o superior a la cifra indicada en el artículo anterior se aplicarán a todos los lotes, a los efectos de publicidad, las disposiciones del mismo" (136).

En relación con los contratos de servicios, el artículo 204 se remite a dicho artículo 136 sustituyendo el importe.

En la Disposición Adicional segunda 11 se indica que:

"En los municipios de población inferior a 5.000 habitantes, en los contratos de obras cuyo período de ejecución exceda al de un presupuesto anual, podrán redactarse proyectos independientes relativos a cada una de las partes de la obra, siempre que éstas sean susceptibles de utilización separada en el sentido del uso general o del servicio, o puedan ser sustancialmente definidas, y preceda autorización concedida por el Pleno de la Corporación, adoptada con el voto favorable de la mayoría absoluta legal de sus miembros, autorización que no podrá ser objeto de delegación”.

A su vez, el Informe de la Junta Consultiva de Contratación Administrativa 41/00, de 30 de octubre de 2000 señala que:

"La división por lotes del objeto de un contrato está prevista en los artículos 68, 136 y 204 de la LCAP, siendo el primero el que por su carácter general, debe ser examinado, señalando que coincide con el artículo 69 de la redacción primitiva de la LCAP, aplicable por razón de fechas, sin más variación que la supresión en el Texto Refundido, por considerarlo inútil y reiterativo, del segundo párrafo del apartado 3 expresivo de que si el contenido de las diferentes partes fuera sustancialmente idéntico, podrá celebrarse un sólo contrato para la adjudicación de las mismas.

La primera consideración que hay que hacer es la de que la regulación de la división por lotes, tanto en las Directivas comunitarias, de donde proceden los preceptos de la LCAP, como en esta última, persigue un objetivo fundamental reflejado en el apartado 2

\footnotetext{
${ }^{41}$ Ahora Resolución de 23 de diciembre de 2015 (BOE de 30/12/2015).

${ }^{42}$ Artículo 136. División por lotes:

"1. Cuando la obra esté dividida en varios lotes y cada lote constituya un contrato, el importe de cada uno se tendrá en cuenta para la determinación de la cuantía a efectos del artículo anterior. No obstante, cuando el importe acumulado de los lotes sea igual o superior a la cifra indicada en el artículo anterior, se aplicarán a todos los lotes, a los efectos de publicidad, las disposiciones del mismo.

2. Sin embargo, el órgano de contratación podrá considerar solamente el importe individualizado de cada lote cuando sea inferior a 166.386.000 pesetas (1.000.000 de euros), con exclusión del Impuesto sobre el Valor Añadido, siempre que el importe acumulado de dichos lotes no sea superior al 20 por 100 del importe acumulado de todos los lotes en los que esté dividida la obra".

Artículo 204. División por lotes:

"Cuando exista división en varios lotes, a efectos de la determinación de la cuantía a que se refiere el artículo anterior, se aplicarán las reglas establecidas en el artículo 136, sustituyendo la cifra de 166.386.000 pesetas (1.000.000 de euros) que figura en su apartado 2 por la de 13.310 .880 pesetas (80.000 euros)".
} 
del artículo 68 en el sentido de que no puede fraccionarse un contrato con objeto de disminuir la cuantía del mismo y eludir así los requisitos de publicidad, el procedimiento o la forma de adjudicación que corresponda. A esta finalidad responden también las reglas que para la valoración de los lotes se reflejan en los artículos 136 y 205 de la LCAP. En el presente supuesto es indudable que, por razón de la cuantía, la división en cinco lotes no altera las reglas de publicidad, procedimiento o forma de adjudicación que corresponde y, por tanto, debe afirmarse que no existe la objeción fundamental utilizable contra la división por lotes, sin que, por otro lado, pueda entenderse que se infringen los demás requisitos de la división por lotes (artículo 68 del Texto Refundido y artículo 69 de la redacción primitiva de la Ley de Contratos de las Administraciones Públicas) de la necesidad de justificar la división y de que los lotes sean susceptibles de utilización y aprovechamiento separado o así lo exija la naturaleza del objeto".

Es de interés como precedente el Dictamen de la Abogacía General del Estado de 28 de julio de 2006 sobre la posibilidad de establecer en los pliegos el requisito de que los contratistas puedan únicamente licitar o resultar adjudicatarios de un único lote, que admite la posibilitad de establecer limitaciones para licitar, pero no admite fijar limitaciones para adjudicar, todo ello en el marco de la normativa entonces vigente. $(\text { TRLCAP })^{43}$.

22) Real Decreto 1098/2001 de 2 de octubre, por el que se aprueba el Reglamento General de Contratación de las Administraciones Públicas, que en su artículo 67.5 dispone que:

"En los contratos de suministro los pliegos de cláusulas administrativas particulares, además de los datos expresados en el apartado 2, contendrán los siguientes:

a) Posibilidad de licitar, en su caso, por la totalidad del objeto del contrato o por los lotes que se establezcan".

A su vez, el artículo $125^{44}$ habla de la "obra completa".

23) Ley 30/2007, de Contratos del Sector Publico.

Establece en el artículo $74^{45}$, de igual modo que la ley 13/95 y Decreto Legislativo 2/2000, dos supuestos en que no es posible el fraccionamiento de los contratos:

\footnotetext{
${ }^{43}$ Vid. Informe de la Junta Consultiva de Contratación de Madrid 1/2002 de 19 de abril, e Informe 1/2004, de 26 de abril.

${ }^{44}$ Artículo 125. Proyectos de obras:

"1. Los proyectos deberán referirse necesariamente a obras completas, entendiéndose por tales las susceptibles de ser entregadas al uso general o al servicio correspondiente, sin perjuicio de las ulteriores ampliaciones de que posteriormente puedan ser objeto y comprenderán todos y cada uno de los elementos que sean precisos para la utilización de la obra.

2. Podrán considerarse elementos comprendidos en los proyectos de obras aquellos bienes de equipo que deben ser empleados en las mismas mediante instalaciones fijas siempre que constituyan complemento natural de la obra y su valor suponga un reducido porcentaje en relación con el presupuesto total del proyecto.

3. Cuando se trata de obras que por su naturaleza o complejidad necesiten de la elaboración de dos o más proyectos específicos y complementarios, la parte de obra a que se refiera cada uno de ellos será susceptible de contratación independiente, siempre que el conjunto de los contratos figure un plan de contratación plurianual.

4. Los proyectos relativos a obras de reforma, reparación o conservación y mantenimiento deberán comprender todas las necesarias para lograr el fin propuesto".

${ }^{45}$ Artículo 74 . Objeto del contrato:
} 
No podrá fraccionarse un contrato con objeto de disminuir la cuantía del mismo y eludir así los requisitos:

a) de publicidad,

b) el procedimiento o la forma de adjudicación que corresponda ${ }^{46}$.

En relación con la admisión del fraccionamiento, añade un supuesto nuevo, que no figuraba en la normativa anterior (siempre que ... "constituya una unidad funcional" ${ }^{47}$ ): "Cuando el objeto del contrato admita fraccionamiento y así se justifique debidamente en el expediente, podrá preverse la realización independiente de cada una de sus partes mediante su división en lotes, siempre que estos:

-sean susceptibles de utilización o aprovechamiento separado y constituyan una unidad funcional,

-o así lo exija la naturaleza del objeto".

Añade además otra novedad en el siguiente párrafo: “Asimismo podrán contratarse separadamente prestaciones diferenciadas dirigidas a integrarse en una obra, tal y como esta es definida en el artículo 6, cuando dichas prestaciones gocen de una sustantividad propia que permita una ejecución separada, por tener que ser realizadas por empresas que cuenten con una determinada habilitación.

“1. El objeto de los contratos del sector público deberá ser determinado.

2. No podrá fraccionarse un contrato con la finalidad de disminuir la cuantía del mismo y eludir así los requisitos de publicidad o los relativos al procedimiento de adjudicación que correspondan.

3. Cuando el objeto del contrato admita fraccionamiento y así se justifique debidamente en el expediente, podrá preverse la realización independiente de cada una de sus partes mediante su división en lotes, siempre que estos sean susceptibles de utilización o aprovechamiento separado y constituyan una unidad funcional, o así lo exija la naturaleza del objeto.

Asimismo podrán contratarse separadamente prestaciones diferenciadas dirigidas a integrarse en una obra, tal y como ésta es definida en el artículo 6, cuando dichas prestaciones gocen de una sustantividad propia que permita una ejecución separada, por tener que ser realizadas por empresas que cuenten con una determinada habilitación.

En los casos previstos en los párrafos anteriores, las normas procedimentales y de publicidad que deben aplicarse en la adjudicación de cada lote o prestación diferenciada se determinaran en función del valor acumulado del conjunto, salvo lo dispuesto en los artículos 14.2, 15.2 y 16.2 ".

${ }^{46}$ Vid. Informe 2/2016, de la Comisión consultiva de Andalucía: "En Informe 9/2009, de 15 de junio, nos pronunciábamos sobre la relación existente entre la contratación menor y el fraccionamiento de los contratos, señalando en éste último Informe que "los diversos aspectos planteados por el órgano consultante en torno a la problemática del fraccionamiento en la contratación pública, se encuentran íntimamente unidos a la categoría legal de los contratos menores ya que, en la generalidad de los casos, el uso de la contratación menor y su apariencia de legalidad constituye el cauce habitual que se emplea para incumplir los correspondientes preceptos legales sobre publicidad y sobre procedimiento de adjudicación". Añade, "En este sentido, la existencia de diversos contratos menores, tramitados simultáneamente o consecutivamente, que tienen por objeto diversas prestaciones que, consideradas en su conjunto, forman una unidad operativa o funcional, puede ser un indicio de que se ha fraccionado un contrato indebidamente- y esto es así con independencia de que el adjudicatario sea diferente en cada contrato, dado que lo que se fracciona es el objeto del contrato-. Ello no obstante, como se ha dicho, este hecho es un mero indicio que debe ser objeto de un análisis más detallado".

47 Vid. Informe 1/09, de 25 de septiembre de 2009. "3.-Existe fraccionamiento del objeto de contrato siempre que se divida éste con la finalidad de eludir los requisitos de publicidad o los relativos al procedimiento de adjudicación correspondiente, y ello, aunque se trate de varios objetos independientes, si entre ellos existe la necesaria unidad funcional u operativa. Correlativamente no existirá fraccionamiento siempre que se trate de diversos objetos que no estén vinculados entre sí por la citada unidad. 4. Para la determinación de si existe o no fraccionamiento del objeto del contrato es irrelevante la existencia o no de vinculaciones accionariales o de otra índole entre los adjudicatarios de los contratos". 
En los casos previstos en los párrafos anteriores, las normas procedimentales y de publicidad que deben aplicarse en la adjudicación de cada lote o prestación diferenciada se determinaran en función del valor acumulado del conjunto, salvo lo dispuesto en los artículos $14.2^{48}, 15.2^{49}$ y $16.2^{50 "}$.

La Directiva 2004/18 disponía al respecto en su artículo 9.5. a) que:

"Cuando una obra prevista o un proyecto de compra de servicios pueda dar lugar a la adjudicación simultánea de contratos por lotes separados, se deberá tener en cuenta el valor global estimado de la totalidad de dichos lotes".

A su vez, en el artículo 9.5.b) indicaba que:

"Cuando un proyecto tendente a obtener suministros homogéneos pueda dar lugar a la adjudicación simultánea de contratos por lotes separados, se deberá tener en cuenta el valor estimado de la totalidad de dichos lotes para la aplicación de las letras a) y b) del artículo 7. Cuando el valor acumulado de los lotes iguale o supere el umbral establecido en el artículo 7, la presente Directiva se aplicará a la adjudicación de cada lote”.

Por último, el artículo 93.2 de la Ley 30/2007 establece que:

"El expediente deberá referirse a la totalidad del objeto del contrato, sin perjuicio de lo previsto en el apartado 3 del artículo 74 acerca de su eventual división en lotes, a efectos de la licitación y adjudicación”.

El cálculo del valor estimado cuando la realización de una obra, la contratación de unos servicios o la obtención de unos suministros homogéneos pueda dar lugar a la adjudicación simultánea de contratos por lotes separados se regula en el Articulo $76^{51}$.

24) Ley 31/2007, de 30 de octubre, sobre procedimientos de contratación en los sectores del agua, la energía, los transportes y los servicios postales.

\footnotetext{
${ }^{48}$ Artículo 14.2:

“2. En el supuesto previsto en el artículo 76.7, cuando el valor acumulado de los lotes en que se divida la obra iguale o supere la cantidad indicada en el apartado anterior, se aplicarán las normas de la regulación armonizada a la adjudicación de cada lote. No obstante, los órganos de contratación podrán exceptuar de estas normas a los lotes cuyo valor estimado sea inferior a un millón de euros, siempre que el importe acumulado de los lotes exceptuados no sobrepase el 20 por ciento del valor acumulado de la totalidad de los mismos".

${ }^{49}$ Artículo 15.2:

“2. En el supuesto previsto en el artículo 76.8, cuando el valor acumulado de los lotes en que se divida el suministro iguale o supere las cantidades indicadas en el apartado anterior, se aplicarán las normas de la regulación armonizada a la adjudicación de cada lote. No obstante, los órganos de contratación podrán exceptuar de estas normas a los lotes cuyo valor estimado sea inferior a 80.000 euros, siempre que el importe acumulado de los lotes exceptuados no sobrepase el 20 por ciento del valor acumulado de la totalidad de los mismos."

${ }^{50}$ Artículo 16.2:

"En el supuesto previsto en el artículo 76.7, cuando el valor acumulado de los lotes en que se divida la compra de servicios iguale o supere los importes indicados en el apartado anterior, se aplicarán las normas de la regulación armonizada a la adjudicación de cada lote. No obstante, los órganos de contratación podrán exceptuar de estas normas a los lotes cuyo valor estimado sea inferior a 80.000 euros, siempre que el importe acumulado de los lotes exceptuados no sobrepase el 20 por ciento del valor acumulado de la totalidad de los mismos."

${ }^{51}$ Artículo 76.7. Cálculo del valor estimado de los contratos:

"Cuando la realización de una obra, la contratación de unos servicios o la obtención de unos suministros homogéneos pueda dar lugar a la adjudicación simultánea de contratos por lotes separados, se deberá tener en cuenta el valor global estimado de la totalidad de dichos lotes".
} 
Se regulan aspectos de la contratación en lotes en el artículo 17.

25) Decreto Legislativo 3/2011, por el que se aprueba el Texto Refundido de la Ley de Contratos del Sector Público.

Así, mientras la Directiva 2004/18/CE únicamente contiene previsiones sobre la división en lotes del objeto de los contratos en relación con las reglas de cálculo del valor estimado de los contratos públicos, estableciendo que para determinarlo debe tenerse en cuenta el valor global estimado de la totalidad de los lotes (artículo 9), el Texto refundido de la Ley de Contratos del Sector Público, aprobado por el Real decreto legislativo 3/2011, de 14 de noviembre (de ahora adelante, TRLCSP), además de establecer las reglas para el cálculo del valor estimado de los contratos divididos en lotes y determinar las normas aplicables a cada uno de los lotes (artículos 14.2, 15.2, $16.2,86.3$ y 88.7), posibilita la división en lotes del objeto de los contratos cuando éste admita fraccionamiento y se justifique debidamente y siempre que los lotes sean susceptibles de utilización o aprovechamiento separado y constituyan una unidad funcional, o lo exija la naturaleza del objeto ${ }^{52}$.

Es relevante el Informe 31/12, de 7 de mayo de 2013 de la Junta Consultiva de Contratación Administrativa "Posibilidad de realizar un conjunto de obras sin consideración de fraccionamiento" ${ }^{\text {"53 }}$, donde extraemos las siguientes conclusiones:

$1^{\circ}$.- Si la prestación que lo constituya es divisible, a partir de ahí, resulta necesario que cada una de ellas constituya un conjunto independiente ${ }^{54}$.

$2^{\circ}$.- Que no haya ánimo defraudatorio, esto es, que en ningún caso la división en lotes sirva para infringir los principios de publicidad y de concurrencia, o se haga con la intención de eludir la aplicación de estos principios en el procedimiento de contratación.

$3^{\circ}$.- Siempre que se mantenga el contrato en su unidad, aunque luego se proceda a la división en lotes del mismo, a efectos de seguir el correspondiente procedimiento en el que se cumplan las reglas de publicidad y concurrencia, manteniéndose sus límites

52 Vid. Nota Informativa 2/2014, de la Secretaría Técnica de la Junta Consultiva de Contratación Administrativa. Cataluña. Asunto: Aplicación del artículo 46 de la Directiva 2014/24/UE del Parlamento Europeo y del Consejo, de 26 de febrero de 2014, sobre contratación pública y por la que se deroga la Directiva 2004/18/CE, relativo a la división de contratos en lotes.

53 "Por tanto, , como vemos para fraccionar el objeto de un contrato, los requisitos necesarios para ello son, en primer lugar, el requisito más importante a tener en cuenta es si la prestación que lo constituya es divisible, a partir de ahí, resulta necesario que cada una de ellas constituya un conjunto independiente y, por encima de todo, que no haya ánimo defraudatorio, esto es, que en ningún caso la división en lotes sirva para infringir los principios de publicidad y de concurrencia, o se haga con la intención de eludir la aplicación de estos principios en el procedimiento de contratación. Por tal motivo, siempre que se mantenga el contrato en su unidad, aunque luego se proceda a la división en lotes del mismo, a efectos de seguir el correspondiente procedimiento en el que se cumplan las reglas de publicidad y concurrencia, manteniéndose sus límites cuantitativos por encima de los umbrales que determinan la aplicación de estas reglas, se podrá proceder a la división en lotes de ese contrato. A tal fin, es necesario además que así se justifique en el expediente y que el cálculo del importe o del valor del contrato se mida por el conjunto de lotes y no de forma individualizada uno a uno".

${ }^{54}$ Vid. Informe 7/2016, de la Junta Consultiva de Canarias, relativo a si es posible licitar dos servicios de transporte de forma separada o si han de licitarse conjuntamente: "La finalidad de la prohibición del fraccionamiento contractual es evitar el fraude legal al eludir determinadas obligaciones en materia de publicidad y relativas a los procedimientos de adjudicación, las cuales dependen del valor estimado del contrato. Sin embargo, no existe obligación de agrupar en un solo contrato prestaciones distintas por el simple hecho de que compartan la misma naturaleza jurídica y puedan ejecutarse de forma conjunta, si son independientes entre sí y es posible contratarlas de manera independiente y explotarlas en análogo sentido". 
cuantitativos por encima de los umbrales que determinan la aplicación de estas reglas, se podrá proceder a la división en lotes de ese contrato ${ }^{55}$.

$4^{\circ}$.- Es necesario además que así se justifique en el expediente.

$5^{\circ}$.- Que el cálculo del importe o del valor del contrato se mida por el conjunto de lotes y no de forma individualizada uno a uno.

En este sentido Isabel Gallego Córcoles ${ }^{56}$ ha destacado que "desde el punto de vista teórico es difícil que se cometa fraude de ley al fraccionar un contrato, puesto que el $\mathrm{art}^{\mathrm{o}}$ 86.3 del TRLCSP, último párrafo establece que las normas de publicidad que deben aplicarse para la adjudicación de cada lote se determinarán en función del valor acumulado del conjunto, desapareciendo así la objeción fundamental utilizable contra la división en lotes".

Por su parte la Junta Consultiva de Contratación Administrativa ${ }^{57}$ ha señalado que "con carácter general le corresponde al órgano de contratación decidir si para dar satisfacción a varias necesidades tramita uno o varios expedientes de contratación. Esta discrecionalidad para configurar jurídicamente la licitación y contratación de dos o más prestaciones encuentra su límite en el principio de no división fraudulenta del objeto del contrato que establece el artículo 86.2 del TRLCSP. El citado principio solo operará cuando pueda hablarse de "fragmentación" como tal, esto es, cuando entre las diferentes prestaciones (o partes de éstas) exista un vínculo operativo".

El Tribunal Administrativo Central de Recursos Contractuales entendió que "el principio general establecido en el TRLCSP es la no división en lotes de los contratos a celebrar por las Administraciones Públicas, siendo criterio de este Tribunal (en este sentido, resoluciones 138/2012, 143/2012, 187/2012, 210/2012, 220/2012 o 227/2012), el respeto a la discrecionalidad del órgano de contratación para elaborar los lotes de acuerdo con sus necesidades y las funcionalidades que se cubren".

En cuanto al fraccionamiento reproduce en su artículo $86^{58}$ el artículo 74 de la Ley $30 / 2007$ y en cuanto al expediente de contratación, se remite al artículo $109^{59}$.

\footnotetext{
${ }^{55}$ Vid. Resolución 571/2016 del TACRC (15 de julio de 2016): "cabe concluir que cuando el órgano de contratación pretende contratar una obra, suministro o servicio para satisfacer una determinada necesidad, existiendo una única finalidad técnica y económica de las diferentes prestaciones que se contratan, la licitación ha de efectuarse en un único procedimiento, el cual podrá en su caso dividirse en lotes, de conformidad con lo dispuesto en el artículo 86 TRLCSP, pero sin que dicha división permita al órgano de contratación eludir la aplicación del procedimiento que corresponda en función del valor estimado del total de las prestaciones a contratar".

56 GALLEGO CÓRCOLES, I., "Comentarios a los artículos 22 a 94", en AA.VV., Contratación del sector Público Local (Coordinador: Castro Abella), Wolters Kluwer España, S.A., Madrid, 2013, $3^{\text {a }}$ ed., págs. 576 y ss.

${ }^{57}$ Vid. Informe 12/15, de 6 de abril de 2016 de la Junta Consultiva de Contratación Administrativa.

${ }^{58}$ Artículo 86. Objeto del contrato:

“1. El objeto de los contratos del sector público deberá ser determinado.

2. No podrá fraccionarse un contrato con la finalidad de disminuir la cuantía del mismo y eludir así los requisitos de publicidad o los relativos al procedimiento de adjudicación que correspondan.

3. Cuando el objeto del contrato admita fraccionamiento y así se justifique debidamente en el expediente, podrá preverse la realización independiente de cada una de sus partes mediante su división en lotes, siempre que éstos sean susceptibles de utilización o aprovechamiento separado y constituyan una unidad funcional, o así lo exija la naturaleza del objeto.

Asimismo podrán contratarse separadamente prestaciones diferenciadas dirigidas a integrarse en una obra, tal y como ésta es definida en el artículo 6, cuando dichas prestaciones gocen de una sustantividad
} 
El cálculo del valor estimado cuando la realización de una obra, la contratación de unos servicios o la obtención de unos suministros homogéneos pueda dar lugar a la adjudicación simultánea de contratos por lotes separados se regula en el Articulo 88.7. Cuando la realización de una obra, la contratación de unos servicios o la obtención de unos suministros homogéneos pueda dar lugar a la adjudicación simultánea de contratos por lotes separados, se deberá tener en cuenta el valor global estimado de la totalidad de dichos lotes. ${ }^{60}$

La Resolución 113/2013 del Órgano Administrativo de Recursos Contractuales del País Vasco se plantea si la superación por la oferta del recurrente de varios de los precios unitarios en los que se descomponen los lotes de la licitación es motivo suficiente para su exclusión, cuando no se ha superado el presupuesto máximo del lote ${ }^{61}$.

propia que permita una ejecución separada, por tener que ser realizadas por empresas que cuenten con una determinada habilitación.

En los casos previstos en los párrafos anteriores, las normas procedimentales y de publicidad que deben aplicarse en la adjudicación de cada lote o prestación diferenciada se determinarán en función del valor acumulado del conjunto, salvo lo dispuesto en los artículos 14.2, 15.2 y 16.2”.

Artículo 88. Cálculo del valor estimado de los contratos:

"7. Cuando la realización de una obra, la contratación de unos servicios o la obtención de unos suministros homogéneos pueda dar lugar a la adjudicación simultánea de contratos por lotes separados, se deberá tener en cuenta el valor global estimado de la totalidad de dichos lotes".

${ }^{59}$ Artículo 109. 2:

"El expediente deberá referirse a la totalidad del objeto del contrato, sin perjuicio de lo previsto en el apartado 3 del artículo 86 acerca de su eventual división en lotes, a efectos de la licitación y adjudicación".

${ }^{60}$ Artículo 14.2:

"En el supuesto previsto en el artículo 88.7, cuando el valor acumulado de los lotes en que se divida la obra iguale o supere la cantidad indicada en el apartado anterior, se aplicarán las normas de la regulación armonizada a la adjudicación de cada lote. No obstante, los órganos de contratación podrán exceptuar de estas normas a los lotes cuyo valor estimado sea inferior a un millón de euros, siempre que el importe acumulado de los lotes exceptuados no sobrepase el 20 por 100 del valor acumulado de la totalidad de los mismos".

Artículo 15.7:

"En el supuesto previsto en el artículo 88.7 cuando el valor acumulado de los lotes en que se divida el suministro iguale o supere las cantidades indicadas en el apartado anterior, se aplicarán las normas de la regulación armonizada a la adjudicación de cada lote. No obstante, los órganos de contratación podrán exceptuar de estas normas a los lotes cuyo valor estimado sea inferior a 80.000 euros, siempre que el importe acumulado de los lotes exceptuados no sobrepase el 20 por 100 del valor acumulado de la totalidad de los mismos".

Artículo 16. 2:

"En el supuesto previsto en el artículo 88.7, cuando el valor acumulado de los lotes en que se divida la compra de servicios iguale o supere los importes indicados en el apartado anterior, se aplicarán las normas de la regulación armonizada a la adjudicación de cada lote. No obstante, los órganos de contratación podrán exceptuar de estas normas a los lotes cuyo valor estimado sea inferior a 80.000 euros, siempre que el importe acumulado de los lotes exceptuados no sobrepase el 20 por 100 del valor acumulado de la totalidad de los mismos".

61 "Para ello, debe partirse de la relevancia de los citados precios unitarios, deducida del contenido de los Pliegos y demás documentos contractuales. La superación de un precio unitario señalado por la Administración, aunque ello no implicase superar el presupuesto máximo global porque el exceso se compensara con descensos en otros precios unitarios, supondría alterar las previsiones de la Administración en cuanto al número de unidades de la prestación afectada que se estima que van a demandarse, y podría suponer tener que aceptar una proposición que ofertara un precio unitario igual al presupuesto máximo previsto para un tipo de prestación aunque eso implicara que sólo podría adquirirse una unidad estando estimada la adquisición de, por ejemplo, cientos de ellas. Tal resultado absurdo sería contrario al sentido común, pues desvirtuaría la definición previa de las necesidades administrativas que 
Por su parte el órgano administrativo de recursos contractuales de Cataluña en Resolución n 55 de fecha 5 noviembre 2012 declara contrario a la legalidad un pliego que establecía que los licitadores no podían presentar sus ofertas a más de 4 lotes de los 12 lotes totales ${ }^{62}$.

\section{SU REGULACIÓN EN LAS DIRECTIVAS EUROPEAS ${ }^{63}$ Y EN OTROS DOCUMENTOS EUROPEOS DE CONTRATACIÓN, ASÍ COMO EN LA JURISPRUDENCIA DEL TRIBUNAL DE JUSTICIA DE LA UNIÓN EUROPEA}

\subsection{ANTECEDENTES}

-Directiva 71/305, de 26 julio 1971, que indica en su artículo 7.2 que:

"Ningún contrato podrá ser fraccionado con el objeto de sustraerlo a la aplicación del presente artículo".

-Directiva 93/36, cuyo artículo 5.6 dispone que:

"No podrá fraccionarse ningún proyecto de compra de una cantidad determinada de suministros con el fin de sustraerse a la aplicación de la presente Directiva".

-Directiva 93/37, que establece en su artículo 6.4 que:

"No se podrá fraccionar ninguna obra ni contrato con objeto de sustraerse a la aplicación de la presente Directiva".

-Directiva 93/38, cuyo artículo 14.13 expone que:

"Las entidades contratantes no podrán substraerse a la aplicación de la presente Directiva dividiendo los contratos o empleando modalidades particulares de cálculo del valor de los contratos".

-Directiva 92/50, que en su artículo 7.3 señala que:

"La elección del método de valoración de un contrato no podrá utilizarse para sustraer dicho contrato a la aplicación de la presente Directiva, como tampoco podrá fraccionarse ningún proyecto de contratación de un determinado número de servicios con el propósito de sustraerlo a la aplicación del presente artículo".

A su vez, en el 7.4, respecto al cálculo del valor estimado, añade:

"Cuando dichos servicios se subdividan en distintos lotes, cada uno de los cuales sea objeto de un contrato, para calcular el valor del importe antes mencionado deberá tenerse en cuenta el valor de cada lote.

se pretende satisfacer (artículo 1 TRLCSP), fundamento último de la actividad contractual de las entidades del sector público".

62 "En el cas concret que ens ocupa no estan justificats els possibles problemes en la gestió en el cas que una mateixa empresa fos adjudicatària de la totalitat o la majoria de lots. Per tant, l'actual redacció dels plecs vulnera el principi de lliure concurrència previstos als articles 1 i 139 del TRLCSP en tant limita $o$ restringeix l'accés de les empreses licitadores a ofertar per tots els lots o per un número superior a quatre". ${ }^{63}$ Vid. MUÑOZ ZAPATA, D., "La división del contrato en lotes tras la aprobación de la cuarta generación de Directivas”, Contratación Administrativa Práctica, nº136, 2015, págs. 42 a 63. 
Cuando el valor de los lotes iguale o supere dicho importe, las disposiciones de la presente Directiva se aplicarán a todos los lotes. Las entidades adjudicadoras podrán eximir del cumplimiento de lo dispuesto en el apartado 1 aquellos lotes cuyo valor estimado, sin IVA, sea inferior a 80000 ecus, siempre y cuando el importe acumulado de todos los lotes exentos no sea superior al $20 \%$ del valor acumulado del conjunto de los lotes".

-Directiva 2004/17, que en su artículo 17.2 estipula que:

"Las entidades adjudicadoras no podrán substraerse a la aplicación de la presente Directiva dividiendo los proyectos de obras o los proyectos de adquisición de productos o de prestación de servicios destinados a obtener una determinada cantidad de suministros o de servicios ni empleando modalidades particulares de cálculo del valor de los contratos".

-Directiva 2004/18, cuyo artículo 9.3 contiene la siguiente previsión:

"No podrá fraccionarse ningún proyecto de obra ni ningún proyecto de compra tendente a obtener una determinada cantidad de suministros y/o de servicios con vistas a sustraerlo a la aplicación de la presente Directiva".

Por lo que respecta a la Jurisprudencia del Tribunal de Justicia de la Unión Europea (en adelante TJUE), cabe destacar la Sentencia de 5 de octubre de 2000, Asunto C$16 / 1998^{64}$, que vino a establecer importantes criterios en relación con la materia y que la Resolución 507/2016 del TACRC resume en los siguientes puntos:

“a) Dado el concepto de obra contenido en la Directiva, para determinar si estamos ante una única obra, con diversas prestaciones, o ante obras distintas ha de atenderse a la finalidad técnica y económica a que responde la licitación (considerando 38).

b) La existencia de una única obra a estos efectos no depende de factores tales como que la competencia para su licitación corresponda en exclusiva a un poder adjudicador o a varios o que su ejecución pueda ser efectuada por uno o varios empresarios (considerando 43).

c) El hecho de que en otras ocasiones se haya optado por efectuar una sola licitación para todos los trabajos, no implica que estemos ante una única obra (considerando 59).

d) En todo caso, cada supuesto debe valorarse en función de su contexto y de sus propias particularidades (considerando 65)".

La sentencia de 15 de marzo de 2012 dictada en el asunto C-574/2010, siguiendo la citada Resolución, fija unos importantes criterios:

“a) En primer lugar, el hecho de que la Directiva defina los contratos de servicios en sentido negativo en relación con el concepto de contratos de obra y de suministros, no significa que no le sean aplicables las reglas, principios generales y objetivos del Derecho de la Unión en materia de contratos públicos (considerando 34).

b) El hecho de que la naturaleza de los contratos de servicios sea diferente del contrato de obras no es suficiente para no aplicar a aquéllos el criterio de funcionalidad desarrollado por el Tribunal en la sentencia de 5 de octubre de 2000. Por ello, para apreciar si las diferentes prestaciones objeto del contrato, así como las distintas fases del

${ }^{64}$ Ver en igual sentido la Sentencia del TJUE de 11 de julio de 2013, dictada en el asunto T-358/08. 
mismo deben ser consideradas como constitutivas de un único contrato, debe verificarse el carácter unitario de su función económica y técnica (considerando 41).

c) Las razones presupuestarias o la existencia de prestaciones de distinta naturaleza no son motivo suficiente para admitir el fraccionamiento del contrato, pues en todo caso podría haberse licitado un solo procedimiento, dividiéndolo en lotes para las distintas fases y prestaciones, pudiendo además prever en los pliegos que la adjudicación del contrato se encuentre condicionada a la existencia de crédito presupuestario suficiente (considerando 46).

d) Las prestaciones objeto de licitación eran en todo caso prestaciones típicas de los servicios de arquitectura que tenían el mismo contenido, a saber, esencialmente, la concepción y planificación de las obras a realizar y la supervisión de su ejecución, en relación con un único proyecto arquitectónico (considerando 44).

f) Por todo ello, concluye que las distintas prestaciones de arquitectura que eran objeto del litigio constituían un único contrato de servicios que debió haberse licitado con arreglo a la Directiva 2004/18/CE (considerando 51)”.

\subsection{CÓdIGO EUROPEO DE BUENAS PRÁCTICAS PARA FACILITAR EL ACCESO DE LAS PYME A LOS CONTRATOS PÚBLICOS, COMISIÓN DE LAS COMUNIDADES EUROPEAS DE 25 DE JUNIO DE $2008^{65}$}

Hace referencia a la subdivisión en lotes: "Subdividir los contratos en lotes. Las Directivas sobre contratación pública permiten que los contratos se adjudiquen por lotes separados. La subdivisión de las compras públicas en lotes facilita, evidentemente, el acceso de las PYME, tanto en términos cuantitativos (el tamaño de los lotes puede corresponderse mejor con la capacidad productiva de la PYME) como cualitativos (puede haber una correspondencia más estrecha entre el contenido de los lotes y el sector de especialización de la PYME). Por otra parte, la subdivisión de los contratos en lotes, favoreciendo así la participación de PYME, intensifica la competencia, lo que redunda en beneficio de los poderes adjudicadores, siempre que tal subdivisión sea viable y resulte adecuada a la luz de las obras, suministros y servicios de que se trate. En este contexto, los poderes adjudicadores habrán de tener presente que, aun estando autorizados a restringir el número de lotes por los que los licitadores pueden presentar ofertas, no deben hacer uso de esa facultad de manera que altere las condiciones de competencia leal. Por otra parte, conceder la posibilidad de licitar por un número ilimitado de lotes presenta la ventaja de no disuadir a los contratistas generales de participar ni desincentivar el crecimiento de las empresas. A este respecto, cabe

\footnotetext{
${ }^{65}$ Vid:

http://ec.europa.eu/geninfo/query/index.do?QueryText=C\%C3\%B3digo+europeo+de+buenas+pr\%C3\%A 1cticas+para+facilitar+el+acceso+de+las+PYME+a+los+contratos+p\%C3\%BAblicos\&op=B\%C3\%BAs queda\&swlang=es\&form build id=form0qfzWuDTNFITEn2dCD1nItZdAYBoWNARQICFEN7 9kw\&form_id=nexteuropa_europa_search_sear ch_form
} 
mencionar las siguientes disposiciones y prácticas nacionales de Austria, Francia, Hungría, Rumanía, Lituania"66.

\subsection{DIRECTIVA 2014/23/UE DEL PARLAMENTO EUROPEO Y DEL CONSEJO DE 26 DE FEBRERO DE 2014 RELATIVA A LA ADJUDICACIÓN DE CONTRATOS DE CONCESIÓN}

Esta Directiva contiene normas en relación con los contratos mixtos, las normas aplicables deben determinarse en función del objeto principal del contrato cuando las distintas partes que constituyen este último no sean objetivamente separables ${ }^{67}$.

Por lo que se refiere a los contratos mixtos que pueden dividirse, el poder o entidad adjudicador podrá en todo momento adjudicar contratos independientes para las partes separadas del contrato mixto, en cuyo caso las disposiciones que han de aplicarse a cada

\footnotetext{
66 "La normativa Austríaca, en 2008, faculta a los poderes adjudicadores para decidir si adjudicar un contrato global o subdividirlo en lotes separados. Al adoptar la oportuna decisión, los poderes adjudicadores han de atender a los aspectos de naturaleza económica o técnica.

En Francia, en 2008, al objeto de fomentar la mayor competencia posible, la norma general consiste en adjudicar contratos por lotes separados. No obstante, los poderes adjudicadores pueden otorgar contratos globales si consideran que, en ese caso concreto, la subdivisión en lotes restringiría la competencia, o podría encarecer o dificultar técnicamente la ejecución del contrato, o si el poder adjudicador no está en condiciones de garantizar la coordinación de la ejecución del contrato.

En algunos estados miembros (Hungría, Rumanía), además de fomentarse la subdivisión de contratos en lotes, existen disposiciones en la normativa nacional con arreglo a las cuales los criterios de selección deben estar en relación y guardar proporción con los distintos lotes y no con el valor agregado de los mismos. Prácticas aplicadas en Irlanda, como también en otros estados miembros, es práctica habitual de numerosos poderes adjudicadores, al convocar ofertas para importantes contratos de construcción, publicar y adjudicar los contratos correspondientes a algunos de los ámbitos especializados (servicios eléctricos, servicios mecánicos, contratos de instalación de material técnico especializado, etc.) a distintos operadores económicos por separado, los cuales deben trabajar en concertación con el operador económico adjudicatario del contrato de coordinación del proyecto en su integridad. Esta práctica facilita la participación de las PYME, sin necesidad de que el poder adjudicador deba ocuparse de las dificultades que comporta coordinar la ejecución de los diversos lotes.

En Lituania, la oficina de contratación pública realiza un análisis previo de los anuncios de licitación antes de enviarlos para su publicación en la base de datos TED y, dentro de ese análisis, recomienda al poder adjudicador, en su caso, la subdivisión del contrato en lotes".

${ }^{67}$ Considerando 29:

"En el caso de los contratos mixtos, las normas aplicables deben determinarse en función del objeto principal del contrato cuando las distintas partes que constituyen este último no sean objetivamente separables. Por consiguiente, conviene precisar el modo en que los poderes y entidades adjudicadores deben determinar si las distintas partes son separables o no. Dicha precisión se basará en la jurisprudencia pertinente del Tribunal de Justicia de la Unión Europea. La determinación se realizará atendiendo a cada caso particular, teniendo en cuenta que la intención expresa o presunta de los poderes o las entidades adjudicadoras de considerar los diversos aspectos que constituyen un contrato mixto como indivisibles no es suficiente, sino que debe apoyarse en pruebas objetivas capaces de justificarla y de establecer la necesidad de celebrar un contrato único. Esta necesidad justificada de celebrar un único contrato podría darse, por ejemplo, en el caso de la construcción de un único edificio, del que una parte vaya a ser utilizada directamente por el poder adjudicador interesado y otra parte vaya a ser aprovechada sobre la base de una concesión, por ejemplo para ofrecer al público plazas de aparcamiento. Debe aclararse que la necesidad de celebrar un único contrato puede deberse a motivos de índole tanto técnica como económica".
} 
parte deben de determinarse exclusivamente teniendo en cuenta las características de ese contrato específico. ${ }^{68}$

En relación con las citadas cuestiones es relevante el artículo 20 de la Directiva, en relación con los contratos mixtos ${ }^{69}$.

Respecto al cálculo estimado en las concesiones que se adjudiquen en forma de lotes separados, hay que acudir al artículo 8 de la Directiva ${ }^{70}$.

\subsection{DIRECTIVA 2014/24/UE DEL PARLAMENTO EUROPEO Y DEL CONSEJO, DE 26 DE FEBRERO DE 2014, SOBRE CONTRATACIÓN PÚBLICA Y POR LA QUE SE DEROGA LA DIRECTIVA 2004/18/CE}

\footnotetext{
${ }^{68}$ Considerando 30:

"En el caso de los contratos mixtos que pueden dividirse, el poder o entidad adjudicador podrá en todo momento adjudicar contratos independientes para las partes separadas del contrato mixto, en cuyo caso las disposiciones que han de aplicarse a cada parte deben de determinarse exclusivamente teniendo en cuenta las características de ese contrato específico. Por otra parte, cuando el poder o entidad adjudicador decida adjudicar un contrato que incluya tanto aspectos de una concesión como otros aspectos, independientemente del valor y del régimen jurídico que se hubiera aplicado a dichos aspectos de otro modo, deben indicarse las normas aplicables a dichos casos. Deben establecerse disposiciones especiales para los contratos mixtos que contienen aspectos relativos a la defensa o a la seguridad, o determinadas partes que no están incluidas en el ámbito de aplicación del TFUE”.

${ }^{69}$ Artículo 20 Contratos mixtos:

"3. En el caso de los contratos que tengan por objeto elementos regulados por la presente Directiva, así como otros elementos, los poderes y entidades adjudicadoras podrán decidir adjudicar contratos separados para partes separadas. Cuando los poderes adjudicadores o entidades adjudicadores decidan adjudicar contratos separados para partes separadas, la decisión sobre el régimen jurídico que se aplica a cualquiera de dichos contratos separados se adoptará sobre la base de las características de la parte separada de que se trate.

Cuando los poderes o entidades adjudicadores decidan adjudicar un contrato único, se aplicará la presente Directiva, a menos que se disponga de otro modo en el apartado 4 del presente artículo o en el artículo 21 , al contrato mixto resultante, con independencia del valor de las partes que de otra forma quedarían sometidas a un régimen jurídico diferente y con independencia del régimen jurídico al que dichas partes hubieran quedado sujetas de otro modo.

4. En el caso de contratos mixtos que contienen elementos de concesiones, así como elementos de contratos públicos regulados por la Directiva 2014/24/UE o de contratos regulados por la Directiva 2014/25/UE, el contrato mixto se adjudicará de conformidad con las disposiciones de la Directiva 2014/24/UE o de la Directiva 2014/25/UE, respectivamente.

5. Cuando las diferentes partes de un determinado contrato no sean objetivamente separables, el régimen jurídico aplicable se determinará en función del objeto principal de ese contrato.

En el caso de los contratos relacionados con elementos de una concesión de servicios y con contratos de suministro, el objeto principal se determinará en función de cuál de los valores estimados de los respectivos servicios o suministros es el más alto".

${ }^{70}$ Artículo 8. Umbrales y métodos de cálculo del valor estimado de las concesiones:

"5. Cuando una obra o un servicio propuestos puedan derivar en que las concesiones se adjudiquen en forma de lotes separados, deberá tenerse en cuenta el valor total estimado de todos los lotes.

6. Cuando el valor acumulado de los lotes iguale o supere el umbral establecido en el presente artículo, la presente Directiva se aplicará a la adjudicación de cada lote".

${ }^{71}$ Entró en vigor el 17 de abril de 2014 y tenía que ser transpuesta por los Estados Miembros, con carácter general, como muy tarde el 18 de abril de 2016.

"El apartado 1 del $\operatorname{art}^{\circ} 46$ (necesidad de justificar expresamente la no división en lotes) y el apartado 2 (posibilidad de limitar el número de lotes a los que se puede licitar y el número máximo de lotes de los que puede resultar adjudicatario un licitador) tienen efecto directo" (documento de los Tribunales administrativos de Contratación pública, sobre Los efectos jurídicos de las directivas de contratación pública ante el vencimiento del plazo de transposición sin nueva Ley de Contratos del Sector Público, 1 de marzo de 2016).
} 
La Directiva 2014/24 representa una novedad en cuanto a regulación de la división del contrato en lotes.

Así, el Considerando 78 indica lo siguiente:

"Debe adaptarse la contratación pública a las necesidades de las PYME. Es preciso alentar a los poderes adjudicadores a utilizar el código de mejores prácticas que se establece en el documento de trabajo de los servicios de la Comisión, de 25 de junio de 2008, titulado "Código europeo de buenas prácticas para facilitar el acceso de las PYME a los contratos públicos", que ofrece orientaciones acerca de cómo aplicar el régimen de contratación pública de forma que se facilite la participación de las PYME. A tal efecto y para aumentar la competencia, procede animar a los poderes adjudicadores a, en particular, dividir grandes contratos en lotes. Esta división podría realizarse de manera cuantitativa, haciendo que la magnitud de cada contrato corresponda mejor a la capacidad de las PYME, o de manera cualitativa, de acuerdo con los diferentes gremios y especializaciones implicados, para adaptar mejor el contenido de cada contrato a los sectores especializados de las PYME o de acuerdo con las diferentes fases ulteriores de los proyectos.

La magnitud y el contenido de los lotes deben ser determinados libremente por el poder adjudicador, el cual, de acuerdo con las normas pertinentes en materia de cálculo del valor estimado de la contratación, debe estar autorizado a adjudicar algunos de los lotes sin aplicar los procedimientos previstos en la presente Directiva. El poder adjudicador debe estar obligado a estudiar la conveniencia de dividir los contratos en lotes, sin dejar de gozar de la libertad de decidir de forma autónoma y basándose en las razones que estime oportunas, sin estar sujeto a supervisión administrativa o judicial. Cuando el poder adjudicador decida que no sería conveniente dividir el contrato en lotes, el informe específico o los pliegos de la contratación deben incluir una indicación de las principales razones que expliquen la elección hecha por el poder adjudicador. Estas razones podrían ser, por ejemplo, el hecho de que el poder adjudicador considere que dicha división podría conllevar el riesgo de restringir la competencia, o hacer la ejecución del contrato excesivamente difícil u onerosa desde el punto de vista técnico, o que la necesidad de coordinar a los diferentes contratistas para los diversos lotes podría conllevar gravemente el riesgo de socavar la ejecución adecuada del contrato.

Los Estados miembros deber seguir gozando de libertad para prolongar sus esfuerzos tendentes a facilitar la participación de las PYME en el mercado de la contratación pública, ampliando el alcance de la obligación de considerar la conveniencia de dividir los contratos en lotes convirtiéndolos en contratos más pequeños, exigiendo a los poderes adjudicadores que aporten una justificación de la decisión de no dividir los contratos en lotes o haciendo obligatoria la división en lotes bajo ciertas condiciones. A este mismo respecto, los Estados miembros deben gozar también de la libertad de facilitar mecanismos para efectuar pagos directos a los subcontratistas".

El Considerando 79, por su parte, señala que:

Vid. Informe 17/2015, de 3 de diciembre, de la Junta Consultiva de Contratación Administrativa de la Comunidad Autónoma de Aragón y el Informe 19/2014, de 17 de diciembre, de la Junta Consultiva de Contratación Administrativa de la Generalitat de Catalunya (Comisión Permanente). 
"Cuando los contratos estén divididos en lotes, los poderes adjudicadores deben estar autorizados a limitar el número de lotes a los que un operador económico puede licitar, por ejemplo, con el fin de preservar la competencia o garantizar la fiabilidad del suministro. También deben estar autorizados a limitar también el número de lotes que pueda adjudicarse a cada licitador".

Por lo que respecta al articulado de esta Directiva, cabe detenerse en el Artículo 46, relativo a la división de contratos en lotes, que en su segundo apartado establece que:

"Los poderes adjudicadores precisarán, en el anuncio de licitación o en la invitación a confirmar el interés, si las ofertas pueden presentarse para uno, varios o todos los lotes.

Los poderes adjudicadores estarán facultados para limitar el número de lotes que puedan adjudicarse a un solo licitador, incluso en el caso de que se puedan presentar ofertas para varios o todos los lotes, siempre que en el anuncio de licitación o en la invitación a confirmar el interés se indique el número máximo de lotes por licitador. Los poderes adjudicadores indicarán en los pliegos de la contratación los criterios o normas objetivos y no discriminatorios que se proponen aplicar para determinar qué lotes serán adjudicados, en caso de que la aplicación de los criterios de adjudicación pueda dar lugar a que a un solo licitador se le adjudique un número de lotes superior al máximo indicado".

El apartado 1 (necesidad de justificar expresamente la no división en lotes) y el apartado 2 (posibilidad de limitar el número de lotes a los que se puede licitar y el número máximo de lotes de los que puede resultar adjudicatario un licitador) tienen efecto directo $^{72}$. El apartado 3 (ofertas integradoras) precisaría, en principio, de un acto de transposición porque se trata de una opción para los Estados miembros. No obstante, se trata de una posibilidad utilizada ampliamente en la práctica y compatible con el actual marco legal (ver, por ejemplo, el artículo 5 del Real Decreto 541/2001, de 18 de 5 de mayo, por el que se establecen determinadas especialidades para la contratación de servicios de telecomunicaciones).

El apartado 4 (posibilidad de que los Estados miembros hagan obligatoria la adjudicación por lotes separados) precisa de transposición y carece de efecto directo. Esto significa que la decisión de articular lotes es una regla o principio de alcance general, pero que no se puede exigir en todas las licitaciones.

\subsection{DIRECTIVA 2014/25/UE DEL PARLAMENTO EUROPEO Y DEL CONSEJO DE 26 DE FEBRERO DE 2014 RELATIVA A LA CONTRATACIÓN POR ENTIDADES QUE OPERAN EN LOS SECTORES DEL AGUA, LA ENERGÍA, LOS TRANSPORTES Y LOS SERVICIOS POSTALES Y POR LA QUE SE DEROGA LA DIRECTIVA 2004/17/CE}

Regula la división en lotes en considerandos 87, 88, 98 y en los siguientes artículos: $16.8,16.9,16.10$ y 65.

\footnotetext{
72 Vid. Documento de trabajo sobre la aplicación de las Directivas Europeas de contratación pública. Tribunales Administrativos de Contratación Pública, 1 de marzo de 2016.
} 


\section{PROYECTO DE LEY DE CONTRATOS DEL SECTOR PÚBLICO, POR LA QUE SE TRANSPONEN AL ORDENAMIENTO JURÍDICO ESPAÑOL LAS DIRECTIVAS DEL PARLAMENTO EUROPEO Y DEL CONSEJO, 2014/23/UE Y 2014/24/UE, DE 26 DE FEBRERO DE $2014^{73}$}

Gimeno Feliú ${ }^{74}$ apunta entre las novedades del proyecto en relación a PYMEs que: "Hay una nueva regulación de la división en lotes de los contratos. Así, se invierte la regla general que se utilizaba hasta ahora, de manera que, solo si no se divide, hay que justificarlo. Se regula la oferta integradora y se puede limitar número de lotes".

En la Exposición de motivos ya se explica la nueva regulación de la división en lotes de los contratos ${ }^{75}$ indicando que se ha introducido una nueva regulación de la división en lotes de los contratos (invirtiéndose la regla general que se utilizaba hasta ahora, debiendo justificarse ahora en el expediente la no división del contrato en lotes, lo que facilitará el acceso a la contratación pública a un mayor número de empresas) ${ }^{76}$.

\subsection{FRACCIONAMIENTO Y DIVISIÓN EN LOTES}

En el Artículo $99^{77}$ (Objeto del contrato) se regulan los supuestos de prohibición del fraccionamiento del contrato, así como la división en lotes.

\footnotetext{
${ }^{73}$ Boletín Oficial de las Cortes generales (Congreso de los Diputados, 2 de diciembre de 2016).

74 GIMENO FELIÚ, J. M., "Principales novedades del Proyecto Ley Contratos Sector Público", 23/01/2017.

http://www.obcp.es/index.php/mod.opiniones/mem.detalle/id.273/relcategoria.121/relmenu.3/chk.d00f48 50d8555aa6e0142cb57e443f0d

75 “Además de las anteriores, se encuentran aquí como medidas de apoyo a las PYMES todas las medidas de simplificación del procedimiento y reducción de cargas administrativas, introducidas con el objetivo de dar un decidido impulso a las empresas. Como medidas más específicas, se ha introducido una nueva regulación de la división en lotes de los contratos (invirtiéndose la regla general que se utilizaba hasta ahora, debiendo justificarse ahora en el expediente la no división del contrato en lotes, lo que facilitará el acceso a la contratación pública a un mayor número de empresas); y, se incluye de forma novedosa como criterio de solvencia que tendrá que justificar el adjudicatario del contrato el cumplir con los plazos establecidos por la normativa vigente sobre pago a proveedores, medida que pretende contribuir a que las PYMES con las que subcontrate el adjudicatario cobrarán sus servicios en plazo".

${ }^{76}$ El Consejo Económico y Social en Dictamen 8/2015 señaló que "para asegurar la ejecución correcta del contrato, la división por lotes debería hacerse por unidades completas de producción y por actividades productivas independientes".

77 Artículo 99:

“1. El objeto de los contratos del sector público deberá ser determinado.

2. No podrá fraccionarse un contrato con la finalidad de disminuir la cuantía del mismo y eludir así los requisitos de publicidad o los relativos al procedimiento de adjudicación que correspondan.

3. Cuando el objeto del contrato admita fraccionamiento, podrá preverse la realización independiente de cada una de sus partes mediante su división en lotes.

Cuando el órgano de contratación decida no dividir en lotes el objeto del contrato, deberá justificarlo debidamente en el expediente, salvo en los casos de contratos de concesión de obras o de concesión de servicios.

En todo caso se entenderá que son motivos válidos, a efectos de justificar la no división en lotes del objeto del contrato, entre otros que el órgano de contratación estime oportunos, los siguientes:
} 
De igual modo, en el artículo 116, al hablar del expediente de contratación, se señala:

"2. El expediente deberá referirse a la totalidad del objeto del contrato, sin perjuicio de lo previsto en el apartado del artículo 99 para los contratos adjudicados por lotes"78.

Se establecen los mismos supuestos de prohibición de fraccionamiento que en el TRLCSP, es decir:

"No podrá fraccionarse un contrato con la finalidad de disminuir la cuantía del mismo

a) El hecho de que, a juicio del órgano de contratación, la división en lotes del objeto del contrato conllevara el riesgo de restringir la competencia.

b) El hecho de que, a juicio del órgano de contratación, la realización independiente de las diversas prestaciones comprendidas en el objeto del contrato dificultaran la correcta ejecución del mismo desde el punto de vista técnico; o bien que el riesgo para la correcta ejecución del contrato proceda de la naturaleza del objeto del mismo, al implicar la necesidad de coordinar la ejecución de las diferentes prestaciones, cuestión que podría verse imposibilitada por su división en lotes y ejecución por una pluralidad de contratistas diferentes.

4. Cuando el órgano de contratación proceda a la división en lotes del objeto del contrato, este podrá introducir las siguientes limitaciones, justificándolas debidamente en el expediente:

a) Podrá limitar el número de lotes para los que un mismo candidato o licitador puede presentar oferta.

b) También podrá limitar el número de lotes que pueden adjudicarse a cada licitador.

Cuando el órgano de contratación considere oportuno introducir alguna de las dos limitaciones a que se refieren las letras a) y b) anteriores, así deberá indicarlo expresamente en el anuncio de licitación y en el pliego de cláusulas administrativas particulares.

Cuando se introduzca la limitación a que se refiere la letra b) anterior, además deberán incluirse en los pliegos de cláusulas administrativas particulares los criterios o normas que se aplicarán cuando, como consecuencia de la aplicación de los criterios de adjudicación, un licitador pueda resultar adjudicatario de un número de lotes que exceda el máximo indicado en el anuncio y en el pliego. Estos criterios o normas en todo caso deberán ser objetivos y no discriminatorios.

5. Cuando el órgano de contratación hubiera decidido proceder a la división en lotes del objeto del contrato y, además, permitir que pueda adjudicarse más de un lote al mismo licitador, aquel podrá adjudicar a una oferta integradora, siempre y cuando se cumplan todos y cada uno de los requisitos siguientes:

a) Que esta posibilidad se hubiere establecido en el pliego que rija el contrato y se recoja en el anuncio de licitación. Dicha previsión deberá concretar la combinación o combinaciones que se admitirá, en su caso, así como la solvencia y capacidad exigida en cada una de ellas.

b) Que se trate de supuestos en que existan varios criterios de adjudicación.

c) Que previamente se lleve a cabo una evaluación comparativa para determinar si las ofertas presentadas por un licitador concreto para una combinación particular de lotes cumpliría mejor, en conjunto, los criterios de adjudicación establecidos en el pliego con respecto a dichos lotes, que las ofertas presentadas para los lotes separados de que se trate, considerados aisladamente.

d) Que los empresarios acrediten la solvencia económica, financiera y técnica correspondiente, o, en su caso, la clasificación, al conjunto de lotes por los que licite.

6. Cuando se proceda a la división en lotes, las normas procedimentales y de publicidad que deben aplicarse en la adjudicación de cada lote o prestación diferenciada se determinarán en función del valor acumulado del conjunto, calculado según lo establecido en el 101, salvo que se dé alguna de las excepciones a que se refieren los artículos 20.2, 21.2 y 22.2.

7. En los contratos adjudicados por lotes, y salvo que se establezca otra previsión en el pliego que rija el contrato, cada lote constituirá un contrato, salvo en casos en que se presenten ofertas integradoras, en los que todas las ofertas constituirán un contrato".

78 "La solución que se ha adoptado es prever -cuando la naturaleza del contrato y las necesidades para su correcta ejecución lo permitan- la división en lotes de los contratos de forma que empresas de pequeño tamaño especializadas en la realización de determinadas prestaciones, pudieran concurrir a la licitación de los lotes, dado que por sus características podrían quedar excluidas del procedimiento para adjudicar un contrato único de mayor volumen. Esta vía de acceso a la contratación, especialmente diseñada para la PYME, permitirá ampliar significativamente el número de contratos y el volumen económico de los mismos a que se pueden acceder" (Memoria de impacto normativo del proyecto de Ley de Contratos del Sector Público, noviembre 2016). 
y eludir así los requisitos de publicidad ${ }^{79} \mathrm{o}$ los relativos al procedimiento de adjudicación que correspondan”.

\subsection{NECESIDAD DE JUSTIFICACIÓN DE LA NO DIVISIÓN EN LOTES}

La novedad se encuentra en la previsión de que cuando el órgano de contratación decida no dividir en lotes el objeto del contrato, deberá justificarlo debidamente en el expediente, salvo en los casos de contratos de concesión de obras o de concesión de servicios.

Es decir:

1- La no división en lotes hay que justificarla en el expediente.

2- La única excepción son los contratos de concesión de obras o de concesión de servicios.

Pilar Batet Jiménez ${ }^{80}$ señala que "los tribunales deben rechazar cualquier justificación genérica en el caso de que no se haya optado por establecer lotes, y exigir un detalle técnico y/ o económico del contrato en concreto que justifique tal decisión".

\subsection{MOTIVOS VÁLIDOS PARA JUSTIFICAR LA NO DIVISIÓN EN LOTES}

El proyecto de ley regula a su vez una tipología no cerrada de motivos que son válidos para justificar la no división en lotes ${ }^{81}$ :

En todo caso se entenderá que son motivos válidos, a efectos de justificar la no división en lotes del objeto del contrato, entre otros que el órgano de contratación estime oportunos, los siguientes:

a) El riesgo de restringir la competencia.

El hecho de que, a juicio del órgano de contratación, la división en lotes del objeto del contrato conllevara el riesgo de restringir la competencia.

\footnotetext{
${ }^{79}$ Artículo 18.2 de la Directiva 2014/24:

"La contratación no será concebida con la intención de excluirla del ámbito de aplicación de la presente Directiva ni de restringir artificialmente la competencia. Se considerará que la competencia está artificialmente restringida cuando la contratación se haya concebido con la intención de favorecer o perjudicar indebidamente a determinados operadores económicos".

80 Vid. BATET JIMENEZ, P., "La división del objeto del contrato en lotes", Gabilex: Revista del Gabinete Jurídico de Castilla- La Mancha, nº, junio 2016, págs. 93 a 131.

${ }^{81}$ La Resolución 298/2017 del Tribunal Administrativo Central de Recursos Contractuales ha puesto de manifiesto que:

"Cuando el poder adjudicador decida que no sería conveniente dividir el contrato en lotes, el informe específico o los pliegos de la contratación debe incluir una indicación de las principales razones que expliquen la elección hecha por el poder adjudicador. Estas razones podrían ser, por ejemplo, el hecho de que el poder adjudicador considere que dicha división podría conllevar el riesgo de restringir la competencia, o hacer la ejecución del contrato excesivamente difícil u onerosa desde el punto de vista técnico, o que la necesidad de coordinar a los diferentes contratistas para los diversos lotes podría conllevar gravemente el riesgo de socavar la ejecución adecuada del contrato".
} 
b) Dificultades técnicas o de coordinación de diferentes prestaciones.

Si la realización independiente de las diversas prestaciones comprendidas en el objeto del contrato dificultaran la correcta ejecución del mismo desde el punto de vista técnico, o bien que el riesgo para la correcta ejecución del contrato proceda de la naturaleza del objeto del mismo, al implicar la necesidad de coordinar la ejecución de las diferentes prestaciones, cuestión que podría verse imposibilitada por su división en lotes y ejecución por una pluralidad de contratistas diferentes.

\subsection{LIMITACIONES DEL NÚMERO DE LOTES PARA LOS QUE UN MISMO CANDIDATO O LICITADOR PUEDA PRESENTAR OFERTA Y DEL NÚMERO DE LOTES QUE PUEDEN ADJUDICARSE A CADA LICITADOR}

El diseño y la regulación, en los pliegos o documentos que rigen las licitaciones de los procedimientos de contratación pública, de la división en lotes del objeto de los contratos, así como de la limitación del número de lotes al cual las empresas pueden presentar ofertas y del número de lotes de los que pueden resultar adjudicatarias, tiene que efectuarse $^{82}$ teniendo en cuenta, aparte del objeto y el volumen de los contratos, aspectos tales como la tipología o el fundamento de la división del objeto del contrato (lotes por funcionalidades, por criterios geográficos, por umbrales o franjas económicas, etc.) ${ }^{83}$ y el sector a que se dirige la licitación, así como el perfil y la tipología de empresas llamadas a participar.

Es decir, la división en lotes y la limitación de presentación o de adjudicación puede hacerse:

* de manera cuantitativa, haciendo que la magnitud de cada contrato corresponda mejor a la capacidad de las PYME, tal y como indica el considerando 78 de la Directiva $2014 / 24$.

*de manera cualitativa:

- tipología de bienes o servicios,

- especialización en el mercado,

- funcionalidades,

- criterios geográficos,

- de acuerdo con los diferentes gremios y especializaciones implicados,

\footnotetext{
${ }^{82}$ Vid. Nota informativa 2/2014, de la Secretaría Técnica de la Junta Consultiva de Contratación Administrativa. Cataluña. Asunto: Aplicación del artículo 46 de la Directiva 2014/24/UE del Parlamento Europeo y del Consejo, de 26 de febrero de 2014, sobre contratación pública y por la que se deroga la Directiva 2004/18/CE, relativo a la división de contratos en lotes.

${ }^{83}$ La misma Directiva 24/2014/CE prevé que "esta división podría realizarse de manera cuantitativa, haciendo que la magnitud de cada contrato corresponda mejor a la capacidad de las PYME, o de manera cualitativa, de acuerdo con los diferentes gremios y especializaciones implicados, para adaptar mejor el contenido de cada contrato a los sectores especializados de las PYME o de acuerdo con las diferentes fases ulteriores de los proyectos" (considerando 78).
} 
para adaptar mejor el contenido de cada contrato a los sectores especializados de las PYME o de acuerdo con las diferentes fases ulteriores de los proyectos.

Pero en todo caso entiendo que ha de hacerse de tal modo que favorezca la concurrencia, garantizando además el interés público.

A. Limitación del número de lotes para los que un mismo candidato o licitador pueda presentar oferta

Podrá limitarse el número de lotes para los que un mismo candidato o licitador puede presentar oferta.

Asimismo, en el pliego y en el anuncio se deberá indicar el número máximo de lotes a los que se puede participar.

El proyecto no regula los efectos de la presentación a un mayor número de lotes de los exigidos en el pliego. Habrá que entender que es causa de exclusión en todos los lotes, circunstancia que consideramos que es necesario que se indique claramente en el pliego.

Respecto a la concurrencia de empresas vinculadas y UTES, a efectos de fijar el número máximo de lotes, el proyecto no dice nada al respecto. Entendemos que en el pliego se deberá indicar expresamente si computan o no las empresas vinculadas y las UTEs.

Sin embargo, estimamos que aplicando por analogía el precepto relativo a concurrencia de una empresa de manera individual y formando parte de una UTE, que no podrían concurrir simultáneamente, tal y como como se regula en el artículo 145.3 del TRLCSP $^{84}$. Por lo que respecta a las empresas vinculadas, entendemos que sí será admisible que puedan concurrir, y aplicando por analogía el artículo 145.4 del actual TRLCSP $^{85}$.

En este sentido es relevante la Resolución n²52/2017 del Tribunal Administrativo Central de Recursos Contractuales que señala que la limitación de lotes se refiere taxativamente a una previsión de limitación de adjudicación de varios lotes al mismo licitador, y no a diversos licitadores del mismo grupo".

B. Limitación del número de lotes que pueden adjudicarse a cada licitador. Criterios de aplicación

También podrá limitar el número de lotes que pueden adjudicarse a cada licitador.

\footnotetext{
${ }^{84}$ Artículo 145.3:

“Cada licitador no podrá presentar más de una proposición, sin perjuicio de lo dispuesto en el artículo 147 sobre admisibilidad de variantes o mejoras y en el artículo 148 sobre presentación de nuevos precios o valores en el seno de una subasta electrónica. Tampoco podrá suscribir ninguna propuesta en unión temporal con otros si lo ha hecho individualmente o figurar en más de una unión temporal. La infracción de estas normas dará lugar a la no admisión de todas las propuestas por él suscritas".

${ }^{85}$ Artículo 145.4:

"En los contratos de concesión de obra pública, la presentación de proposiciones diferentes por empresas vinculadas supondrá la exclusión del procedimiento de adjudicación, a todos los efectos, de las ofertas formuladas. No obstante, si sobreviniera la vinculación antes de que concluya el plazo de presentación de ofertas, o del plazo de presentación de candidaturas en el procedimiento restringido, podrá subsistir la oferta que determinen de común acuerdo las citadas empresas. En los demás contratos, la presentación de distintas proposiciones por empresas vinculadas producirá los efectos que reglamentariamente se determinen en relación con la aplicación del régimen de ofertas con valores anormales o desproporcionados previsto en el artículo 152. Se considerarán empresas vinculadas las que se encuentren en alguno de los supuestos previstos en el artículo 42 del Código de Comercio".
} 
En este caso los licitadores pueden presentar sus ofertas a uno, varios o la totalidad de los lotes, pero no podrán ser adjudicatarios de todos, solo podrán serlo por el número máximo que se fije en el pliego.

Además, deberán incluirse en los pliegos de cláusulas administrativas particulares los criterios o normas que se aplicarán cuando, como consecuencia de la aplicación de los criterios de adjudicación, un licitador pueda resultar adjudicatario de un número de lotes que exceda el máximo indicado en el anuncio y en el pliego.

Estos criterios o normas en todo caso deberán ser:

- objetivos

- no discriminatorios

La limitación del número de lotes lleva consigo la dificultad de fijar unos criterios objetivos para determinar qué lotes se adjudican. Pensemos el supuesto de que una empresa concurre a 6 lotes y el pliego limita a tres el número de lotes, y que este licitador ha obtenido la mayor puntuación en los seis lotes. Tal y como se ha indicado en el pliego se deberán establecer previamente los criterios objetivos.

En algunos pliegos se establece que será criterio para adjudicar el contrato la preferencia manifestada por las empresas licitadoras en sus ofertas, si los pliegos o documentos que rigen las licitaciones establecen la posibilidad de incluir esta indicación a los efectos de determinar de qué lotes tiene que resultar adjudicataria la empresa que ha presentado las ofertas más ventajosas económicamente en un número de lotes superior al máximo permitido. Entiendo que este criterio no debe utilizarse, pues deja en manos del licitador elegir los lotes, considero que el criterio debería ser automático, es decir la Administración elegirá aquellas ofertas en los lotes que supongan un mayor ahorro económico para la Administración, por ejemplo. Solo podría operar este supuesto en los casos de que dicho ahorro económico para la Administración sea igual, en cuyo caso sí podría darse posibilidad de elegir. En relación con esta cuestión se ha pronunciado el Tribunal Administrativo Central de Recursos Contractuales en la Resolución 207/2017 de 24 de febrero de 2017.

A continuación, con idea de plantear alguna casuística que podría darse sobre este tema, planteamos las siguientes hipótesis:

Hipótesis en la limitación del número de lotes que pueden adjudicarse a un solo licitador (supuesto de limitación a 3 lotes en un conjunto de 6 lotes totales):

- Empate de licitadores:

○ Criterios de desempate del pliego

- El que gane el desempate podrá ser adjudicatario dentro del límite de los 3 lotes.

- Baja con ofertas temerarias: No hay adjudicación, pues es un trámite de audiencia previo.

- Si no se justifica la baja se adjudica al siguiente no incurso en baja temeraria y no computa en el límite de ese lote, pero en ningún caso el siguiente licitador podría ser adjudicatario de más de tres lotes. 
- No presenta el licitador la documentación en la fase de requerimiento de documentación a la oferta más ventajosa, (no justifica los medios, no constituye la garantía, etc...) o renuncia a la adjudicación de un lote concreto.

○ No podrá solicitar optar a la adjudicación de otro lote en sustitución de éste.

- Se inicia el trámite de inhabilitación.

- Otra empresa no presenta el requerimiento y al siguiente licitador, con oferta más ventajosa:

- Se le adjudica si está en el límite de los 3

- Si no está en el límite de los tres

- No se computa, pues ya es adjudicatario de tres lotes.

- Se propondría al siguiente licitador.

- Ofertas con empresas Vinculadas:

- No les afecta de manera conjunta el límite de 3 lotes, pero sí individualmente.

- Se presenta a la licitación de forma individual y en UTE:

○ ¿Computa o no computa en el límite máximo de tres lotes?

Entendemos que sí, y siempre que concurran a distintos lotes. Si concurren al mismo lote de forma individual y en UTE, sería causa de exclusión.

- Supuesto de recurso administrativo o jurisdiccional contra la adjudicación:

Si se estima el recurso de otra empresa, podría darse la circunstancia de que afectase a la distribución o límites de los otros lotes.

- Supuesto de que no hubiera ofertas para algún lote y un licitador que se presentó a los 6 lotes ya es adjudicatario de 3 lotes:

Entendemos que en este supuesto el pliego debería exceptuar la limitación de lotes, pues se daría la paradoja de que tendría que declararse desierto el lote.

C. Disposiciones Comunes

Forma:

Cuando el órgano de contratación considere oportuno introducir alguna de las dos limitaciones, deberá indicarlo expresamente:

- en el anuncio de licitación

- y en el pliego de cláusulas administrativas particulares.

Es decir, establece una doble constancia, en el pliego y en el anuncio.

Entendemos que en el anuncio bastará con indicar el número máximo de lotes, y que en el pliego deberán figurar además los criterios objetivos. 
Normas procedimentales y de publicidad:

Cuando se proceda a la división en lotes, las normas procedimentales y de publicidad que deben aplicarse en la adjudicación de cada lote o prestación diferenciada se determinarán en función del valor acumulado del conjunto, calculado según lo establecido en el 101, salvo que se dé alguna de las excepciones a que se refieren los artículos $20.2^{86}, 21.2^{87}$ y $22.2^{88}$.

Cálculo del Valor Estimado:

De acuerdo con lo dispuesto en el Artículo 101. $12^{89}$, relativo al valor estimado:

"se deberá tener en cuenta el valor global estimado de la totalidad de dichos lotes.

Igualmente, cuando una obra o un servicio propuestos puedan derivar en la adjudicación simultánea de contratos de concesión de obras o de concesión de servicios por lotes separados, deberá tenerse en cuenta el valor global estimado de todos los lotes".

Este artículo se corresponde con el artículo 5.8 de la Directiva 2014/24, que dispone que:

"Cuando una obra prevista o un proyecto de prestación de servicios pueda dar lugar a la adjudicación de contratos por lotes separados, se tendrá en cuenta el valor total estimado de la totalidad de dichos lotes. Cuando el valor acumulado de los lotes sea igual superior al umbral establecido en el artículo 4, la presente Directiva se aplicará a la adjudicación de cada lote. Cuando un proyecto de adquisición de suministros pueda dar

\footnotetext{
${ }^{86}$ Artículo 20.2:

"En el supuesto previsto en el artículo 101.12 relativo al cálculo del valor estimado en los contratos de obras que se adjudiquen por lotes separados, cuando el valor acumulado de los lotes en que se divida la obra iguale o supere la cantidad indicada en el apartado anterior, se aplicarán las normas de la regulación armonizada a la adjudicación de cada lote. No obstante lo dispuesto en el párrafo anterior, los órganos de contratación podrán exceptuar de estas normas a los lotes cuyo valor estimado sea inferior a un millón de euros, siempre que el importe acumulado de los lotes exceptuados no sobrepase el 20 por 100 del valor acumulado de la totalidad de los mismos".

87 Artículo 21.2:

"En el supuesto previsto en el artículo 101.12 relativo al cálculo del valor estimado en los contratos que se adjudiquen por lotes separados, cuando el valor acumulado de los lotes en que se divida el suministro iguale o supere las cantidades indicadas en el apartado anterior, se aplicarán las normas de la regulación armonizada a la adjudicación de cada lote. No obstante, los órganos de contratación podrán exceptuar de estas normas a los lotes cuyo valor estimado sea inferior a 80.000 euros, siempre que el importe acumulado de los lotes exceptuados no sobrepase el 20 por 100 del valor acumulado de la totalidad de los mismos".

88 Artículo 22.2:

"En el supuesto previsto en el artículo 101.12 relativo al cálculo del valor estimado en los contratos que se adjudiquen por lotes separados, cuando el valor acumulado de los lotes en que se divida la contratación de servicios iguale o supere los importes indicados en el apartado anterior, se aplicarán las normas de la regulación armonizada a la adjudicación de cada lote. No obstante, los órganos de contratación podrán exceptuar de estas normas a los lotes cuyo valor estimado sea inferior a 80.000 euros, siempre que el importe acumulado de los lotes exceptuados no sobrepase el 20 por 100 del valor acumulado de la totalidad de los mismos".

${ }^{89}$ Artículo 101.12:

"Cuando la realización de una obra, la contratación de unos servicios o la obtención de unos suministros destinados a usos idénticos o similares pueda dar lugar a la adjudicación simultánea de contratos por lotes separados, se deberá tener en cuenta el valor global estimado de la totalidad de dichos lotes.

Igualmente, cuando una obra o un servicio propuestos puedan derivar en la adjudicación simultánea de contratos de concesión de obras o de concesión de servicios por lotes separados, deberá tenerse en cuenta el valor global estimado de todos los lotes."
} 
lugar a la adjudicación de contratos por lotes separados, se tendrá en cuenta el valor total estimado de todos los lotes al aplicarse el artículo 4, letras b), y c). Cuando el valor estimado de los lotes sea igual o superior al umbral establecido en el artículo 4, la presente Directiva se aplicará a la adjudicación de cada lote".

Garantía provisional en casos de división por lotes:

Por lo que respecta a este tema, cabe aludir al artículo 106, que se refiere a la exigencia y régimen de la garantía provisional y establece lo siguiente:

"En el caso de división en lotes, la garantía provisional se fijará atendiendo exclusivamente al importe de los lotes para los que el licitador vaya a presentar oferta y no en función del importe del presupuesto total del contrato".

Acreditación de solvencia:

En este punto debemos acudir al artículo 140 sobre presentación de la documentación acreditativa del cumplimiento de los requisitos previos, que indica lo siguiente en su letra g:

"Cuando el pliego prevea la división en lotes del objeto del contrato, si los requisitos de solvencia económica y financiera o técnica y profesional exigidos variaran de un lote a otro, se aportará una declaración responsable por cada lote o grupo de lotes al que se apliquen los mismos requisitos de solvencia".

\section{OFERTA INTEGRADORA}

Cuando el órgano de contratación hubiera decidido proceder a la división en lotes del objeto del contrato y, además, permitir que pueda adjudicarse más de un lote al mismo licitador, aquel podrá adjudicar a una oferta integradora, siempre y cuando se cumplan todos y cada uno de los requisitos siguientes:

1) Inclusión en pliego y anuncio. Combinaciones:

Que esta posibilidad se hubiere establecido en el pliego que rija el contrato y se recoja en el anuncio de licitación. Dicha previsión deberá concretar la combinación o combinaciones que se admitirá, en su caso, así como la solvencia y capacidad exigida en cada una de ellas.

2) Que existan varios criterios de adjudicación:

Que se trate de supuestos en que existan varios criterios de adjudicación. Es decir, no es posible cuando existe un único criterio, por ejemplo, factor precio.

3) Evaluación comparativa previa:

Que previamente se lleve a cabo una evaluación comparativa para determinar si las ofertas presentadas por un licitador concreto para una combinación particular de lotes cumpliría mejor, en conjunto, los criterios de adjudicación establecidos en el pliego con respecto a dichos lotes, que las ofertas presentadas para los lotes separados de que se trate, considerados aisladamente. 
4) Acreditación de la solvencia:

Que los empresarios acrediten la solvencia económica, financiera y técnica correspondiente, o, en su caso, la clasificación, al conjunto de lotes por los que licite.

El apartado 3 (ofertas integradoras) precisaría, en principio, de un acto de transposición porque se trata de una opción para los Estados miembros. No obstante, se trata de una posibilidad utilizada ampliamente en la práctica y compatible con el actual marco legal (ver, por ejemplo, el artículo 5 del Real Decreto 541/2001, de 18 de mayo, ${ }^{90}$ por el que se establecen determinadas especialidades para la contratación de servicios de telecomunicaciones), sobre las que existe una importante doctrina del TACRC al respecto. ${ }^{91}$

\section{POSIBILIDAD DE RESERVAR DETERMINADOS LOTES A CENTROS ESPECIALES DE EMPLEO Y EMPRESAS DE INSERCIÓN ${ }^{92}$}

La Disposición adicional cuarta (Contratos reservados) prevé la reserva de determinados lotes a estas entidades ${ }^{93}$.

\footnotetext{
${ }^{90}$ BOE núm. 138, de 9/06/2001. Artículo 5. Objeto del contrato:

"El objeto del contrato definirá las necesidades que se quieran satisfacer mediante la celebración del contrato, realizando una descripción detallada de las mismas, estableciendo, siempre que sea posible, lotes separados de aquellos servicios que por sus características lo permitan. En este caso se podrá prever en el pliego de cláusulas administrativas particulares la posibilidad de presentar también ofertas integradoras de varios o de todos los lotes licitados".

${ }^{91}$ Resoluciones del TACRC de 29 de abril de 2010, 52/2013; de 30 de enero, 523/2015; de 5 de junio, 837/2015; de 18 de septiembre, $\mathrm{n}^{\circ} 211 / 2017$.

${ }^{92}$ Vid. Informe 16/2011 de 8 de junio de la Junta Consultiva de Contratación Administrativa de la Comunidad de Aragón y Artículo 7.2 de la Ley 3/2011, de medidas en materia de contratos del Sector Público de Aragón.

${ }^{93}$ Disposición adicional cuarta (Contratos reservados):

"1. Mediante Acuerdo del Consejo de Ministros o a través del órgano competente en el ámbito de las Comunidades Autónomas y de las Entidades Locales, se fijarán porcentajes mínimos de reserva del derecho a participar en los procedimientos de adjudicación de determinados contratos o de determinados lotes de los mismos a Centros Especiales de Empleo y a empresas de inserción reguladas en la Ley 44/2007, de 13 de diciembre, para la regulación del régimen de las empresas de inserción, que cumplan con los requisitos establecidos en dicha normativa para tener esta consideración, o un porcentaje mínimo de reserva de la ejecución de estos contratos en el marco de programas de empleo protegido, a condición de que el porcentaje de trabajadores con discapacidad o en situación de exclusión social de los Centros Especiales de Empleo, de las empresas de inserción o de los programas sea el previsto en su normativa de referencia y, en todo caso, al menos del 30 por 100.

En el referido Acuerdo del Consejo de Ministros o a través del órgano competente en el ámbito de las Comunidades Autónomas y de las Entidades Locales, se fijarán las condiciones mínimas para garantizar el cumplimiento de lo establecido en el párrafo anterior.

2. En el anuncio de licitación deberá hacerse referencia a la presente disposición".
} 


\section{CONCLUSIONES}

Es positiva la nueva regulación de la Directiva 2014/24, con el fin de favorecer la concurrencia de la pequeña y mediana empresa, al disponer que se deberá justificar la no división en lotes. Es cierto que en todo caso no se podrá fraccionar el contrato con la finalidad de disminuir la cuantía del mismo y eludir así los requisitos de publicidad o los relativos al procedimiento de adjudicación que correspondan.

Respecto a la limitación en el número de lotes en que los operadores pueden concurrir o la limitación del número de lotes que se puedan adjudicar a un solo licitador, debe hacerse previo el correspondiente estudio que garantice el interés público y la eficiencia de la decisión y las condiciones del mercado, favoreciendo la concurrencia.

\section{BIBLIOGRAFÍA}

ALBI, F., Los Contratos municipales, Editorial Horizontes, Valencia, 1944.

BARROS MARTÍNEZ, E., Derecho Local de España, Instituto Editorial Reus, Madrid, 1951.

BATET JIMENEZ, P., "La división del objeto del contrato en lotes", Gabilex: Revista del Gabinete Jurídico de Castilla- La Mancha, nº, junio 2016.

DE PAUlA AGUilerA GONZÁleZ, F., y MODElO BAEZA, J.M., "El fraccionamiento en la contratación administrativa local", El Consultor, n' 17 , quincena 15-29 septiembre 2007.

GALLEGO CÓRCOLES, I., "Comentarios a los artículos 22 a 94", en AA.VV., Contratación del sector Público Local (Coordinador: Castro Abella), Wolters Kluwer España, S.A., Madrid, 2013, $3^{\text {a }}$ ed.

GIMENO FELIÚ, J. M., "Principales novedades del Proyecto Ley Contratos Sector Público", 23/01/2017. http://www.obcp.es/index.php/mod.opiniones/mem.detalle/id.273/relcategoria.121/relm enu.3/chk.d00f4850d8555aa6e0142cb57e443f0d

HERRERA CAMPA, J.J., "Análisis normativo del fraccionamiento del gasto", Revista Cuenta con IGAE, Edición y Distribución: Subdirección General de Información, Documentación y Publicaciones, nº13, Noviembre 2005.

MORENO MOLINA, J.A., Los principios generales de la contratación administrativa, Ed. Bomarzo, Albacete, 2006.

MUÑOZ ZAPATA, D., "La división del contrato en lotes tras la aprobación de la cuarta generación de Directivas", Contratación Administrativa Práctica, nº136, 2015.

VILLAR EZCURRA, J.L., y MARFÁ BADAROUX, J., "Artículo 68. Fraccionamiento del objeto del contrato", en AA.VV., Comentarios a la Ley de contratos de las Administraciones Públicas, Tomo II, Ariño y Asociados, Granada, 2003. 